\title{
Intracellular ATP Influences Synaptic Plasticity in Area CA1 of Rat Hippocampus via Metabolism to Adenosine and Activity-Dependent Activation of Adenosine $A_{1}$ Receptors
}

\author{
Stephanie zur Nedden, ${ }^{1}$ Simon Hawley, ${ }^{2}$ Naomi Pentland, ${ }^{2,3}$ D. Grahame Hardie, ${ }^{2}$ Alexander S. Doney, ${ }^{4}$ \\ and Bruno G. Frenguelli ${ }^{1,3}$ \\ ${ }^{1}$ School of Life Sciences, University of Warwick, Coventry, CV4 7AL, United Kingdom, 2Division of Molecular Physiology, College of Life Sciences, \\ University of Dundee, Dundee, DD1 5EH, United Kingdom, and Departments of ${ }^{3}$ Pharmacology and Neuroscience and ${ }^{4}$ Medicine and Therapeutics, \\ University of Dundee, Ninewells Hospital and Medical School, Dundee, DD1 9SY, United Kingdom
}

The extent to which brain slices reflect the energetic status of the in vivo brain has been a subject of debate. We addressed this issue to investigate the recovery of energetic parameters and adenine nucleotides in rat hippocampal slices and the influence this has on synaptic transmission and plasticity. We show that, although adenine nucleotide levels recover appreciably within $10 \mathrm{~min}$ of incubation, it takes $3 \mathrm{~h}$ for a full recovery of the energy charge (to $\geq 0.93$ ) and that incubation of brain slices at $34^{\circ} \mathrm{C}$ results in a significantly higher ATP/AMP ratio and a threefold lower activity of AMP-activated protein kinase compared with slices incubated at room temperature. Supplementation of artificial CSF with D-ribose and adenine (Rib/Ade) increased the total adenine nucleotide pool of brain slices, which, when corrected for the influence of the dead cut edges, closely approached in vivo values. Rib/Ade did not affect basal synaptic transmission or paired-pulse facilitation but did inhibit long-term potentiation (LTP) induced by tetanic or weak theta-burst stimulation. This decrease in LTP was reversed by strong theta-burst stimulation or antagonizing the inhibitory adenosine $\mathrm{A}_{1}$ receptor suggesting that the elevated tissue ATP levels had resulted in greater activity-dependent adenosine release during LTP induction. This was confirmed by direct measurement of adenosine release with adenosine biosensors. These observations provide new insight into the recovery of adenine nucleotides after slice preparation, the sources of loss of such compounds in brain slices, the means by which to restore them, and the functional consequences of doing so.

\section{Introduction}

The use of brain slices has revolutionized the study of the mammalian CNS, and they have now become a standard preparation in many laboratories and in many areas of neuroscience. Hippocampal brain slices are particularly widely used for studies into the fundamental properties of synaptic transmission and plasticity.

However, it is an unavoidable fact that their preparation is associated with ischemia (decapitation) and tissue trauma (dissection/slice cutting), which will affect metabolic status and result in departure from the in vivo state. Indeed, a substantially compromised energetic state of brain slices at the time of cutting has been demonstrated (Fredholm et al., 1984; Whittingham et al., 1984b), with high energy phosphate levels (ATP, phosphocre-

Received Aug. 3, 2010; revised Feb. 18, 2011; accepted Feb. 24, 2011.

Author contributions: D.G.H., A.S.D., and B.G.F. designed research; S.Z.N., S.H., and N.P. performed research; S.z.N., S.H., and B.G.F. analyzed data; S.z.N., S.H., D.G.H., A.S.D., and B.G.F. wrote the paper.

We thank Jan Lopatar, Abigail Perkins, and Dr. Rajen Mistry for help with slice preparation and adenosine biosensor experiments and Prof. Nicholas Dale for valuable input, including the derivation of the slice thickness equation and use of HPLC equipment. We are grateful to Research into Ageing for funding a studentship to S.Z.N. S.H. was supported by EXGENESIS Integrated Project Grant LSHM-CT-2004-005272 from the European Commission.

Correspondence should be addressed to Prof. Bruno G. Frenguelli, School of Life Sciences, University of Warwick, Coventry CV4 7AL, UK. E-mail: b.g.frenguelli@warwick.ac.uk.

DOI:10.1523/JNEUROSCI.4039-10.2011

Copyright $\odot 2011$ the authors $\quad 0270-6474 / 11 / 316221-14 \$ 15.00 / 0$ atine) in brain slices being as much as 50\% lower than their in situ values (Thomas, 1957; Whittingham et al., 1984a; Schurr and Rigor, 1989). Accordingly, basal conditions in hippocampal slices have been described as reflecting a post-ischemic recovery state (Hossmann, 2008). However, as described as far back as the 1950s (McIlwain et al., 1951; McIlwain, 1952), brain slices do show remarkable metabolic recovery after preparation, and it is now common practice to allow a period of incubation (usually $1 \mathrm{~h}$ ) before they are used for experiments.

Given the widespread use and importance of brain slices to neuroscience, the aims of our study were threefold: first, to assess the metabolic status of brain slices by studying the temperaturedependent recovery and stability of adenine nucleotide levels and energetic parameters, including the activity of AMP-activated protein kinase (AMPK), an enzyme involved in regulation of cellular energy homeostasis and exquisitely sensitive to the cellular ATP/AMP ratio; second, to investigate the potential causes for the reduced ATP content of brain slices compared with reported in vivo values and to evaluate whether the lower ATP levels are attributable to a lack of adenine nucleotide precursors by incubating slices with the free purine base adenine and the sugar precursor of adenylates, D-ribose; finally, to test whether elevated slice ATP levels change the electrophysiological properties of the tissue, such as the probability of transmitter release or the induction and expression of long-term potentiation (LTP). 
Our findings provide new insights into the energetic status of brain slices: they show that the loss of ATP precursors is responsible for the decreased ATP content of brain slices and that, by supplementing the artificial CSF (aCSF) with adenine and D-ribose, the recovery of tissue ATP levels can be improved. However, this has measurable consequences in terms of greater activity-dependent release of extracellular adenosine and, via activation of adenosine $A_{1}$ receptors $\left(A_{1} R s\right)$, the raising of the threshold for the induction of long-term potentiation.

\section{Materials and Methods}

Preparation of brain slices. Male Sprague Dawley rats (17-27 d old) were killed by cervical dislocation in accordance with Schedule 1 of the United Kingdom Government Animals (Scientific Procedures) Act 1986 and with local ethical review procedures. Sagittal brain slices ( $400 \mu \mathrm{m}$ thick), composed of hippocampus and overlying neocortex, were prepared under standardized conditions in ice-cold aCSF containing $10 \mathrm{mM} \mathrm{Mg}^{2+}$ using a Microm HM $650 \mathrm{~V}$ microtome as described previously (Dale et al., 2000; Frenguelli et al., 2007). Slices were either analyzed immediately during cutting for their purine nucleotide content or transferred to the recording chamber or an incubation chamber (50-100 ml) (Edwards et al., 1989) and submerged in continuously circulating, oxygenated standard aCSF at room temperature $\left(22 \pm 0.5^{\circ} \mathrm{C}\right)$ or $34 \pm 1^{\circ} \mathrm{C}$. The composition of the standard aCSF solution included the following (in mM): 124 $\mathrm{NaCl}, 3 \mathrm{KCl}, 2 \mathrm{CaCl}_{2}, 26 \mathrm{NaHCO}_{3}, 1.25 \mathrm{NaH}_{2} \mathrm{PO}_{4}, 10 \mathrm{D}$-glucose, and 1 $\mathrm{MgSO}_{4}$, pH 7.4 (with $95 \% \mathrm{O}_{2} / 5 \% \mathrm{CO}_{2}$ ).

In a separate set of experiments, nucleotide concentrations of (1) the intact hippocampus and cortex and (2) slices of varying thickness were analyzed. For this purpose, one hemisphere was used to dissect and separate hippocampus and cortex, and the other hemisphere was used to cut slices of varying thickness $(200-3600 \mu \mathrm{m})$. Because with the microtome used no slices $>1500 \mu \mathrm{m}$ could be cut automatically, $3600 \mu \mathrm{m}$ had to be measured with a guide. For these experiments, all nucleotide extractions were performed immediately after preparation (zur Nedden et al., 2009).

Nucleotide extraction. To determine the total adenine nucleotide (TAN) content of $400 \mu \mathrm{m}$ brain slices, two slices for each time point [from time of cutting (time 0 ) to $5 \mathrm{~h}$ after cutting at $10 \mathrm{~min}, 30 \mathrm{~min}, 1 \mathrm{~h}$, $2 \mathrm{~h}, 3 \mathrm{~h}$, and $5 \mathrm{~h}$ ] were transferred into ice cold aCSF to stop enzymatic activities. To minimize transfer of aCSF into the reaction mixture, slices were removed with a small spatula into a $1.5 \mathrm{ml}$ microcentrifuge tube containing $1 \mathrm{ml}$ of $5 \%$ perchloric acid (PCA). Nucleotide extraction was performed as described in detail previously (zur Nedden et al., 2009). Extracts were neutralized by a threefold organic extraction with $1 \mathrm{ml}$ of tri- $n$-octylamine dissolved in 1,1,2-trichlorotrifluoroethane $(1: 1 ; \mathrm{v} / \mathrm{v})$. The protein pellet was resuspended in $1 \mathrm{ml}$ of $0.5 \mathrm{M} \mathrm{NaOH}$, and the protein concentration was determined by Bradford assay, with bovine serum albumin (BSA) as standard.

For analysis of the TAN content of whole hippocampus and neocortex and 1200,1500 , and $3600 \mu \mathrm{m}$ slices, the tissue was first homogenized in $500 \mu \mathrm{l}$ of $5 \%$ PCA. The amount of this suspension containing $20 \mathrm{mg}$ wet weight (equivalent to four $200 \mu \mathrm{m}$, two $400 \mu \mathrm{m}$, or one $800 \mu \mathrm{m}$ slice) of the tissue was mixed with 5\% PCA to a final volume of $1 \mathrm{ml}$ and neutralized as described above.

We have shown previously that snap freezing in liquid $\mathrm{N}_{2}$ and freeze thawing of brain tissue results in a degradation of adenine nucleotides and an underestimation of the energy charge (zur Nedden et al., 2009). For this reason, nucleotides were only extracted from fresh brain tissue and were analyzed on the same day.

Protein extraction. For each time point, two to three brain slices were placed in ice-cold aCSF to stop enzymatic activities. Slices were homogenized in $100 \mu \mathrm{l}$ of protein lysis buffer with a Kontes pellet pestle motor (Sigma-Aldrich). The suspension was centrifuged $\left(30 \mathrm{~min}, 4^{\circ} \mathrm{C}, 16,060 \times\right.$ $g$ ), and the supernatant was stored at $-80^{\circ} \mathrm{C}$ for kinase assays and Western blot analysis. The composition of the protein lysis buffer was as follows: 50 mu Tris- $\mathrm{HCl}$, pH 7.5, 0.1 mм EGTA, 1 mm EDTA, 1\% Triton $\mathrm{X}-100,1 \mathrm{~mm}$ sodium orthovanadate, $50 \mathrm{~mm}$ sodium fluoride, $5 \mathrm{~mm}$ sodium pyrophosphate, $270 \mathrm{~mm}$ sucrose, $0.1 \% \beta$-mercaptoethanol, $0.02 \%$ sodium azide, and 1 protease inhibitor tablet for $16.6 \mathrm{ml}$ of lysis buffer.
HPLC. For analysis of purine nucleotides and nucleosides, an ion pair reversed-phase HPLC method with tetrabutylammonium hydrogen sulfate (TBAHS) was used, as described previously (zur Nedden et al., 2009). Analytical separation was performed on a Supelcosil LC-18-T reversedphase column $(150 \times 4.6 \mathrm{~mm}$; inner diameter, $3 \mu \mathrm{m})$, with a gradient profile from $100 \%$ buffer A ( 65 mm potassium phosphate, $\mathrm{pH} 6.0,4 \mathrm{~mm}$ TBAHS) to $100 \%$ buffer B (65 mm potassium phosphate, $\mathrm{pH} 6.0,25 \%$ methanol) in $13 \mathrm{~min}$. Peak identities were confirmed by comparison of the retention times of sample peaks with peaks of standard compounds, spiking the samples with individual standards and by comparison of the UV spectra with standard compounds. Concentrations were calculated by comparing the peak area of sample peaks with calibration curves for peak areas of each standard compound. All concentrations are expressed as nanomoles per milligram of protein.

Kinase assays. AMPK from extracts was immunoprecipitated with a mixture of $\alpha 1$ and $\alpha 2$ antibodies, and AMPK activity in the immunoprecipitates was determined using the AMARA peptide assay as described previously (Hardie et al., 2000; Gadalla et al., 2004).

Western blot analysis. The detection of dual-labeled Western blots by infrared imaging was performed as described previously (Hawley et al., 2003), except that, in the present study, the phosphorylation state of the native full-length protein was determined.

Electrophysiological recordings. Except for one series of experiments, slices (comprising hippocampus and overlying neocortex) were incubated for $3-8 \mathrm{~h}$ in standard aCSF or for $2 \mathrm{~h}$ in aCSF supplemented with 1 $\mathrm{mm}$ ribose $/ 50 \mu \mathrm{M}$ adenine (Rib/Ade) and $1-6 \mathrm{~h}$ in standard aCSF before being transferred to a recording chamber and fully submerged in aCSF at $33.4 \pm 0.2^{\circ} \mathrm{C}$ and a flow rate of $6-7 \mathrm{ml} / \mathrm{min}$. In the other series of experiments, slices were immediately transferred to the recording chamber during slice cutting to monitor the recovery of synaptic transmission in control and Rib/Ade-containing aCSF. A twisted bipolar Teflon-coated tungsten wire was placed to stimulate the Schaffer collateral/commissural pathway every $15 \mathrm{~s}$, and field EPSP (fEPSPs) were recorded from stratum radiatum in area CA1 of the hippocampus with a glass microelectrode filled with aCSF $(1 \mathrm{M} \Omega)$. The stimulus intensity was adjusted to $50-60 \%$ of that required to evoke a population spike. LTP was induced with tetanic stimulation (one train of 100 stimuli at $100 \mathrm{~Hz}$ ) or with theta-burst (TBS) stimulation $(0.5,1,2$, or $3 \times 10$ trains of four stimuli at $100 \mathrm{~Hz}$ repeated at $200 \mathrm{~ms}$ intervals).

Adenosine biosensors. Adenosine and null microelectrode biosensors (50 $\mu \mathrm{m}$ diameter and $500 \mu \mathrm{m}$ length) were purchased from Sarissa Biomedical Ltd. and were used to measure the real-time release of adenosine during LTP induction. The use of the sensors in hippocampal slices has been described previously (Frenguelli et al., 2003, 2007). The adenosine sensor relies on an enzyme cascade immobilized within a matrix on the surface of a platinum/iridium electrode to metabolize adenosine, thereby liberating $\mathrm{H}_{2} \mathrm{O}_{2}$, which is oxidized on the platinum/iridium electrode. This gives rise to an oxidation current proportional to the concentration of adenosine. The null sensor lacks enzymes and is used to establish the presence of any electroactive interferents. Both sensors were inserted into the stratum radiatum of the CA1 region of hippocampal slices between recording and stimulating electrodes. After insertion, slices were allowed to recover for 30-45 min before electrical stimulation for the recording of fEPSPs was started. After a stable fEPSP baseline of 15-20 min was collected, adenosine release was evoked with three TBS given $10 \mathrm{~s}$ apart. fEPSPs, adenosine and null sensor traces were recorded simultaneously. Thirty minutes after LTP induction, sensors were either taken out of the tissue or drugs were applied for 15-30 min before TBS was repeated. After each experiment, sensors were calibrated with $10 \mu \mathrm{M}$ adenosine in the recording chamber. Because no nonspecific electroactive release could be detected on the null sensor, adenosine release was calculated without subtraction of the null trace, and the values are given as $\mu \mathrm{M}^{\prime}$ to reflect that the adenosine sensor measures adenosine and its metabolites (Frenguelli et al., 2007). To integrate the area under the curve of adenosine sensor traces, the baseline had to be set to 0 , which was achieved by subtracting from the sensor trace a linear regression based on $5 \mathrm{~min}$ of baseline.

Statistical analysis. All values are expressed as mean \pm SEM. For the electrophysiological and adenosine sensor measurements, $n$ values refer 
to the number of slices per experimental condition, which for most cases is also equal to the number of animals used. Slices were used in duplicate for nucleotide extraction and in triplicate for protein extraction. In these cases, $n$ values represent the number of animals used. For statistical analysis of more than two groups, one-way ANOVA with Bonferroni's multiple comparison test was applied, whereas for comparisons between two independent groups, unpaired $t$ tests were used. For comparison of the adenosine release before and after application of different drugs, a paired $t$ test was applied. Calculations were performed with Prism 4; $p$ values $<0.05$ were considered as statistically significant.

Chemicals. All HPLC standards, 1,1,2-trichloro-1,1,2-trifluoroethane (HPLC grade), EGTA, EDTA, sodium fluoride, sodium orthovanadate, sodium pyrophosphate, sodium azide, BSA, TBAHS, D-ribose, adenine, 8-cyclopentyltheophylline (8-CPT), nitrobenzylthioinosine (NBTI), dipyridamole (DIPY), $N^{6}$-cyclopentyladenosine $\left(N^{6}\right.$-CPA), sodium polyoxotungstate (POM-1), and the Bradford reagent were obtained from Sigma-Aldrich. Protease inhibitor cocktail tablets and ATP were from Roche. HPLC-grade methanol, perchloric acid, orthophosphoric acid, tri-n-octylamine, Triton X-100, Tris base, and all salts used in the aCSF were obtained from Thermo Fisher Scientific. Protein G Sepharose was from GE Healthcare. Pyridoxalphosphate-6-azophenyl-2',4' -disulfonic acid (PPADS) and forskolin were purchased from Ascent. Sheep antibodies against the $\alpha 1$ and $\alpha 2$ subunits of AMPK were described previously (Woods et al., 1996), and the antibody against the phosphorylated Thr-172 was from Cell Signaling Technologies.

\section{Results}

Metabolic recovery after slice cutting

Recovery of adenine nucleotides

To study the recovery of adenine nucleotides after slice preparation, HPLC analysis of slice extracts was performed on fresh slices immediately after cutting and after various incubation time points in aCSF $(10 \mathrm{~min}$ to $5 \mathrm{~h})$ at room temperature $\left(22^{\circ} \mathrm{C}\right)$ and $34^{\circ} \mathrm{C}$ (Fig. $1 \mathrm{~A}$ ).

Immediately after cutting, ATP, ADP, and AMP were present in nearly equal amounts $(6.0 \pm 0.3,4.0 \pm 0.4$, and $5.2 \pm 0.8$ $\mathrm{nmol} / \mathrm{mg}$ protein, respectively; $n=7$ ) (Fig. $1 B-D$ ) (supplemental Table 1, available at www.jneurosci.org as supplemental material). ATP levels significantly increased after only $10 \mathrm{~min}$ incubation $\left(10.7 \pm 1.0\right.$ and $11.0 \pm 0.9 \mathrm{nmol} / \mathrm{mg}$ protein at $22^{\circ} \mathrm{C}$ and $34^{\circ} \mathrm{C}$, respectively; $n=7 ; p<0.001$, one-way ANOVA) with a concomitant decrease of ADP $(1.9 \pm 0.3$ and $1.5 \pm 0.1 \mathrm{nmol} / \mathrm{mg}$ protein at $22^{\circ} \mathrm{C}$ and $34^{\circ} \mathrm{C}$, respectively; $n=7 ; p<0.001$, one-way ANOVA $)$ and AMP $(1.1 \pm 0.3$ and $0.5 \pm 0.1 \mathrm{nmol} / \mathrm{mg}$ protein at $22^{\circ} \mathrm{C}$ and $34^{\circ} \mathrm{C}$ respectively; $n=7 ; p<0.001$, one-way ANOVA) levels. ATP degradation metabolites (IMP, adenosine, inosine, hypoxanthine, and xanthine) were all elevated at the time of cutting and together accounted for $\sim 5 \mathrm{nmol} / \mathrm{mg}$ protein (supplemental Table 2, available at www.jneurosci.org as supplemental material). The levels of these metabolites declined after slice cutting and stabilized after 10-60 min of incubation.

After the initial recovery, ATP, ADP, and AMP levels did not significantly change during the incubation time points tested (up to $5 \mathrm{~h}$ incubation), and there were no significant differences between adenine nucleotides of slices kept at $22^{\circ} \mathrm{C}$ and $34^{\circ} \mathrm{C}$ (Fig. $1 B-D)$. As a consequence of these complementary changes in individual nucleotides, the total adenine nucleotide pool (TAN = $[\mathrm{ATP}]+[\mathrm{ADP}]+[\mathrm{AMP}])($ Fig. $1 E)$ did not significantly change when slices were transferred from the ice-cold cutting solution $(15.2 \pm 1.1 \mathrm{nmol} / \mathrm{mg}$ protein; $n=7)$ into aCSF at $22^{\circ} \mathrm{C}(13.7 \pm$ $1.4 \mathrm{nmol} / \mathrm{mg}$ protein; $n=7)$ or $34^{\circ} \mathrm{C}(13.0 \pm 1.1 \mathrm{nmol} / \mathrm{mg}$ protein; $n=7$ ), suggesting that most of the accumulated AMP is rephosphorylated to ATP rather than dephosphorylated to adenosine (via cytosolic 5'-nucleotidase, EC 3.1.3.5.) or deaminated to IMP (via AMP deaminase, EC 3.5.4.6.). The TAN pool re- mained stable over an incubation period of $5 \mathrm{~h}$. Average TAN concentrations from all time points tested ( $10 \mathrm{~min}$ to $5 \mathrm{~h}$ ) were $14.1 \pm 0.3 \mathrm{nmol} / \mathrm{mg}$ protein in slices at $22^{\circ} \mathrm{C}$ and $15.4 \pm 0.9 \mathrm{in}$ slices at $34^{\circ} \mathrm{C}$, with ATP accounting for $\sim 85$ and $89 \%$, respectively.

\section{Recovery of energetic parameters and AMPK activity}

Two widely used measures of cellular energetic state are the adenylate energy charge, $\mathrm{EC}=([\mathrm{ATP}]+0.5[\mathrm{ADP}]) /[\mathrm{TAN}]($ Atkinson, 1968), which has a maximum value of 1 when all the adenine nucleotides are in the form of ATP and the ATP/AMP ratio.

Because of the nearly equal amounts of ATP, ADP, and AMP at the time of cutting, the EC was very low $(0.54 \pm 0.03 ; n=7)$ (Fig. 2A) (supplemental Table 3, available at www.jneurosci.org as supplemental material) but recovered significantly after only 10 min incubation at $22^{\circ} \mathrm{C}(0.86 \pm 0.019 ; n=7 ; p<0.001$, one-way ANOVA $)$ and $34^{\circ} \mathrm{C}(0.90 \pm 0.007 ; n=7 ; p<0.001$, one-way ANOVA). After $3 \mathrm{~h}$ the EC stabilized at $0.93 \pm 0.003$ for slices kept at $22^{\circ} \mathrm{C}$ and at $0.95 \pm 0.002$ for slices kept at $34^{\circ} \mathrm{C}$, and, as for adenine nucleotides, there were no significant differences between slices at $22^{\circ} \mathrm{C}$ and $34^{\circ} \mathrm{C}$.

The ATP/AMP ratio significantly recovered from time of cutting (1.4 $\pm 0.4 ; n=7$ ) (Fig. 2B) (supplemental Table 3, available at www.jneurosci.org as supplemental material) after only $10 \mathrm{~min}$ in slices at $34^{\circ} \mathrm{C}(22.9 \pm 2.7 ; n=7 ; p<0.001$, one-way ANOVA $)$, whereas it took $\sim 30 \mathrm{~min}$ to recover in slices incubated at $22^{\circ} \mathrm{C}$ $(20.1 \pm 1.8 ; n=6 ; p<0.001$, one-way ANOVA). Similar to the $\mathrm{EC}$, the ATP/AMP ratio stabilized after $3 \mathrm{~h}$ but with considerable differences between slices incubated at $22^{\circ} \mathrm{C}$ and at $34^{\circ} \mathrm{C}$. At $22^{\circ} \mathrm{C}$, the ATP/AMP ratio ranged between 35.2 and 38.0 , whereas at $34^{\circ} \mathrm{C}$, the ATP/AMP ratio was much higher between 63.5 and 64.2. The differences in the ATP/AMP ratio values between the two incubation temperatures became statistically significant after $30 \min (n=6-8 ; p<0.01$, one-way ANOVA) and remained statistically significant for the rest of the incubation period $(n=$ $5-8 ; p<0.001$, one-way ANOVA).

The cellular ATP/AMP ratio is monitored by AMPK (EC 2.7.11.31), a key sensor and regulator of cellular energy metabolism (Hardie and Hawley, 2001; Hardie, 2007). AMPK is activated by phosphorylation of Thr172 by the upstream kinases LKB1 (Hawley et al., 2003) and calcium/calmodulin-dependent protein kinase kinase $\beta$ (Hawley et al., 2005; Woods et al., 2005). In addition, an increase in cellular AMP provides both allosteric activation of the enzyme and protection of Thr 172 from dephosphorylation, whereas both of these effects are antagonized by high intracellular ATP levels (Hardie et al., 2006; Sanders et al., 2007). Therefore, we investigated whether the lower ATP/AMP ratio in slices at $22^{\circ} \mathrm{C}$ was reflected by a higher AMPK activity.

AMPK activity (Fig. 2C) decreased from $0.066 \pm 0.003 \mathrm{U} / \mathrm{mg}$ protein at time of cutting to $0.04 \pm 0.001 \mathrm{U} / \mathrm{mg}$ protein after 30 min at $22^{\circ} \mathrm{C}(1.6$-fold decrease; $n=3 ; p<0.001$, one-way ANOVA), by which time at $34^{\circ} \mathrm{C}$ AMPK activity had fallen 3.4fold $(n=2)$. After $3 \mathrm{~h}$, AMPK was three times more active in slices at $22^{\circ} \mathrm{C}(0.03 \pm 0.003 \mathrm{U} / \mathrm{mg}$ protein; $n=3)$ than in slices at $34^{\circ} \mathrm{C}$ $(0.01 \pm 0.001 \mathrm{U} / \mathrm{mg}$ protein; $n=3 ; p<0.001$, one-way ANOVA). Western blots (Fig. $2 D$ ) showed that the ratio of phospho-AMPK/total AMPK decreased from 2.8 at time of cutting to 1.9 in slices at $22^{\circ} \mathrm{C}$ and to 1.1 in slices at $34^{\circ} \mathrm{C}$ after $3 \mathrm{~h}$ incubation $(n=2)$ (supplemental Fig. 1, available at www.jneurosci.org as supplemental material). Likewise, the phospho/total ratio of a substrate, acetyl-CoA carboxylase (ACC), decreased from 1.6 at time of cutting to 1.0 in slices at $22^{\circ} \mathrm{C}$ and to 0.5 in slices at $34^{\circ} \mathrm{C}$ after $3 \mathrm{~h}$ incubation (Fig. 2D) (supplemental Fig. 1, available at 
www.jneurosci.org as supplemental material). These observations suggest that, despite similarities between TAN pools and EC values between slices incubated at room temperature and more physiological temperatures, the ATP/AMP ratio can influence the activity of key intracellular enzymes with potentially important consequences for neuronal and glial properties.

\section{Basis of reduced TAN concentration in slices}

EC values of brain slices reported here (Fig. 2A) (supplemental Table 3, available at www.jneurosci.org as supplemental material) are comparable with those reported in vivo (supplemental references, available at www.jneurosci.org as supplemental material). However, absolute TAN levels here (Fig. 1E) (supplemental Table 1, available at www.jneurosci.org as supplemental material) and in the in vitro literature (supplemental references, available at www.jneurosci.org as supplemental material) are $\sim 40-60 \%$ lower than published in vivo values for rat brain, which are typically $\sim 33.6 \pm 4.7 \mathrm{nmol} / \mathrm{mg}$ protein (arithmetic mean \pm SD of all in vivo published data in supplemental references, available at www.jneurosci.org as supplemental material) (Fig. $3 A$ ). In our study, the loss of adenine nucleotides occurred either before or during slice preparation, because TAN levels were already $\sim 55 \%$ ( 18.4 nmol/mg protein) lower at the time of cutting than published in vivo studies. We investigated several possible explanations for this observation.

The ischemic period leads to loss of diffusible ATP degradation products The sum of ATP degradation metabolites (adenosine, inosine, hypoxanthine, xanthine, and IMP) at time of cutting was approximately $\sim 5 \mathrm{nmol} / \mathrm{mg}$ protein (supplemental Table 2, available at www. jneurosci.org as supplemental material). Although, like ADP and AMP levels, these metabolites declined during the first 10-30 min of incubation, there was no corresponding rise in the TAN pool. Thus, they are likely to be lost from the tissue and thereby contribute to the reduced adenine nucleotide content of brain slices.

The tissue suffers from physical damage causing additional loss of adenine nucleotides

To establish whether the dissection of tissue associated with slicing caused additional loss of adenine nucleotides, we determined the TAN content immediately after decapitation/dissection in entire hippocampus and cortex (because slices in this study were composed of hippocampus and overlaying neocortex). The TAN content of intact hippocampal and cortical tissue was higher than
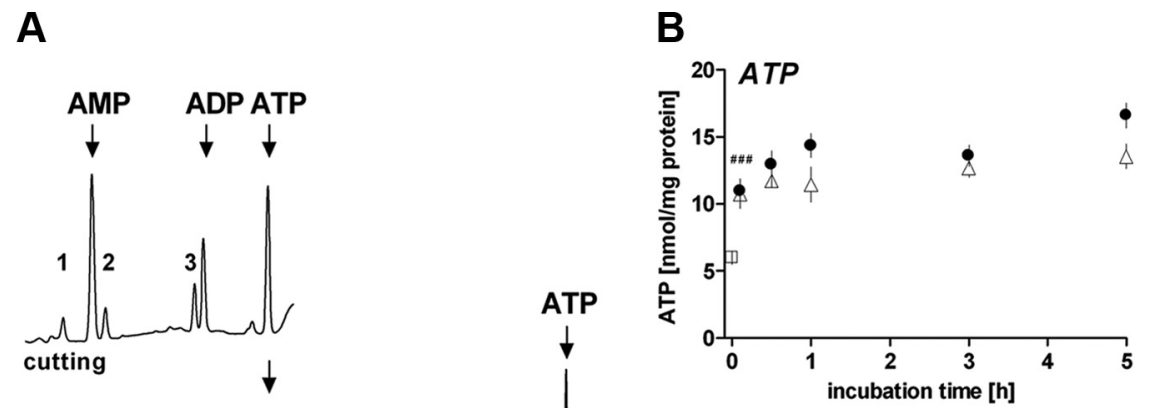

C

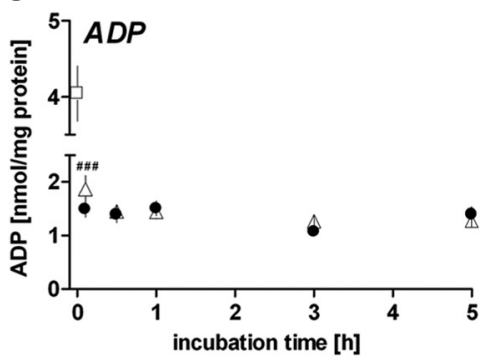

D

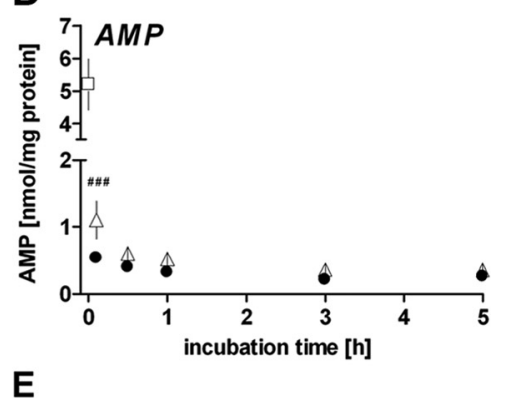

E

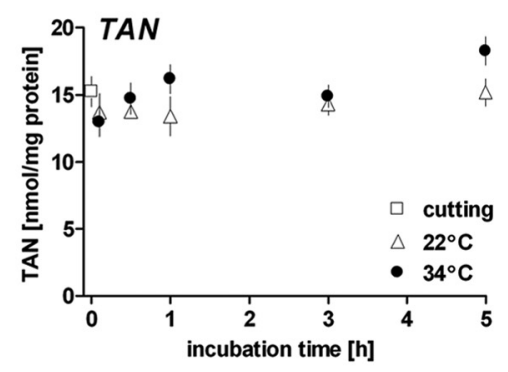

Figure 1. Rapid recovery of adenine nucleotides after slice preparation. $A$, Representative HPLC traces obtained from brain slices after slice cutting and various incubation times in aCSF at room temperature $\left(22^{\circ} \mathrm{C}\right.$; left traces) and $34^{\circ} \mathrm{C}$ (right traces). Note the consistently higher AMP levels in slices incubated at $22^{\circ} \mathrm{C}$. Numbers on traces refer to the following compounds: 1 , adenosine; 2, GDP; 3 , GTP/UTP. Arrowheads indicate, from left to right, AMP, ADP, and ATP; $m A U$, milli absorbance units. $\boldsymbol{B}-\boldsymbol{E}$, Recovery of ATP $(\boldsymbol{B}), \operatorname{ADP}(\boldsymbol{C}), \operatorname{AMP}(\boldsymbol{D})$, and total adenine nucleotides (TAN $=[A T P]+[A D P]+[A M P])(\boldsymbol{E})$ from time of cutting (white squares, time 0 ) and various incubation times $\left(0.1-5 \mathrm{~h}\right.$ ) in aCSF at $22^{\circ} \mathrm{C}$ (white triangles) or $34^{\circ} \mathrm{C}$ (black circles). Values are presented as mean \pm

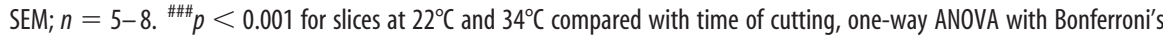
multiple comparison test. When no error bars can be seen, they are smaller than the symbol.

that in combined hippocampal/neocortical slices at $23.0 \pm 2.1$ and $28.9 \pm 2.9 \mathrm{nmol} / \mathrm{mg}$ protein, respectively (Fig. $3 A)(n=5$; $p>0.05$ between hippocampal and cortical tissue, unpaired $t$ test). The value for cortex is close to that reported in vivo (33.6 \pm $4.7 \mathrm{nmol} / \mathrm{mg}$ protein) (Fig. $3 A$ ), but TAN levels in the hippocampus are lower than those reported in vivo. This suggests that the ischemic period during decapitation results in a loss of adenine nucleotides, especially in hippocampal tissue $(\sim 10 \mathrm{nmol} / \mathrm{mg}$ protein, $\sim 29 \%$ ), which additionally requires more physical and 
A

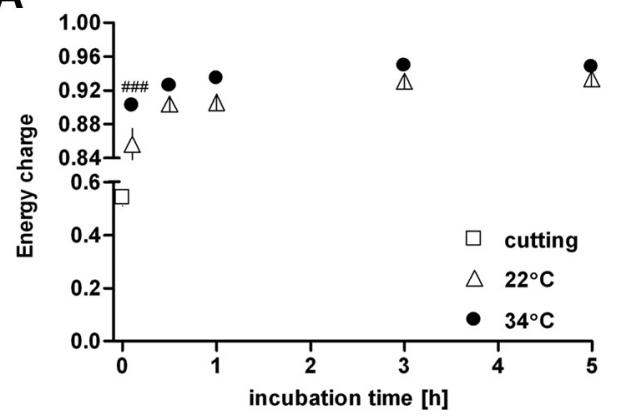

B
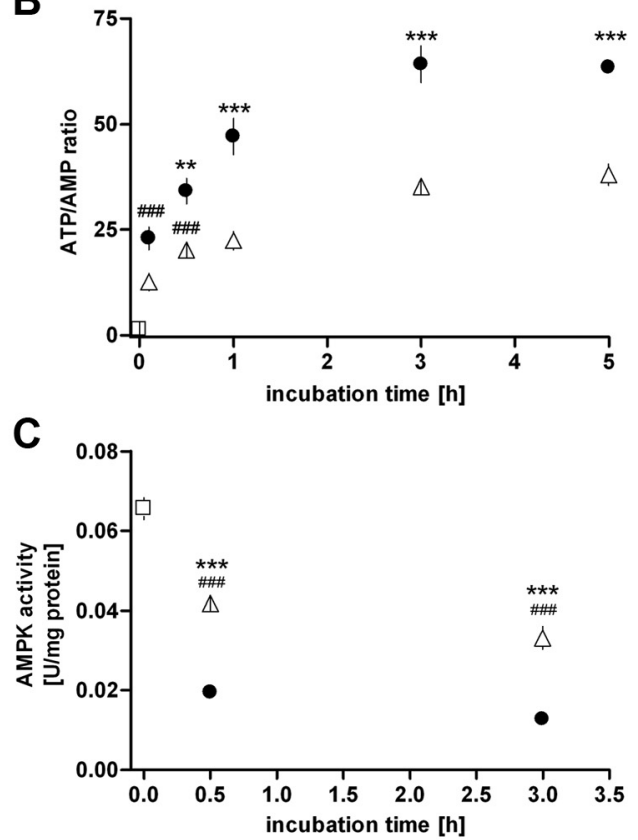

D

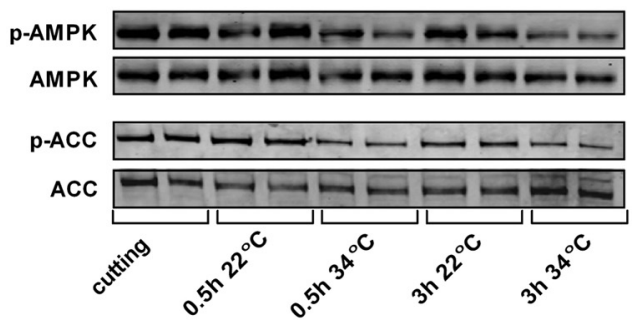

Figure 2. Differential influence of temperature on the recovery of energetic parameters and AMPK activity after slice cutting. Recovery of the tissue energy charge [(ATP + 0.5 ADP)/TAN] is not influenced by temperature $(\boldsymbol{A})$, whereas the ATP/AMP ratio is significantly higher at elevated temperature $(n=5-8)(\boldsymbol{B})$. C, Accordingly, AMPK activity in brain slices, as measured by pseudo-substrate phosphorylation, is lower at higher incubation temperature, reflecting the higher ATP/AMP ratio $\left(n=3\right.$ except for $\left.0.5 \mathrm{~h}, 34^{\circ} \mathrm{C}, n=2\right)$. White squares, Slices at time of cutting (time 0$)$; white triangles, slices incubated in aCSF at room temperature $\left(22^{\circ} \mathrm{C}\right)$; black circles, slices incubated in aCSF at $34^{\circ} \mathrm{C}$. D. Confirmation of increased AMPK activity through Western blot analysis of increased phosphorylation of AMPK (p-AMPK) and a downstream target, $\mathrm{ACC}(\mathrm{p}-\mathrm{ACC})$. Also shown are total AMPK and ACC at different durations and temperature of incubation in two separate sets of slices. All values are presented as mean \pm SEM. \#\#\# $p<$ 0.001 for slices at $22^{\circ} \mathrm{C}$ and $34^{\circ} \mathrm{C}$ compared with time of cutting; ${ }^{* *} p<0.01$, ${ }^{* * *} p<0.001$ compared between slices at $22^{\circ} \mathrm{C}$ and $34^{\circ} \mathrm{C}$, one-way ANOVA with Bonferroni's multiple comparison test. When no error bars can be seen, they are smaller than the symbol.

potentially traumatic dissection for removal. In contrast, neocortex may undergo more rapid cooling when the brain is dropped into ice-cold aCSF, which may better preserve adenine nucleotides.

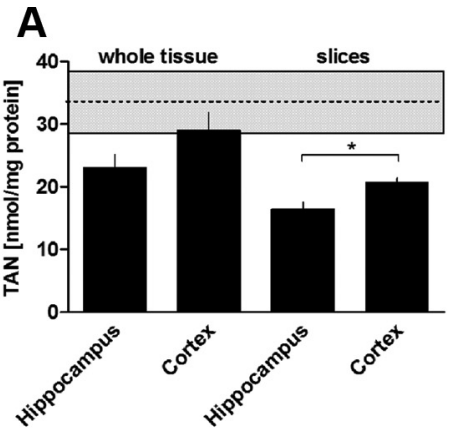

B
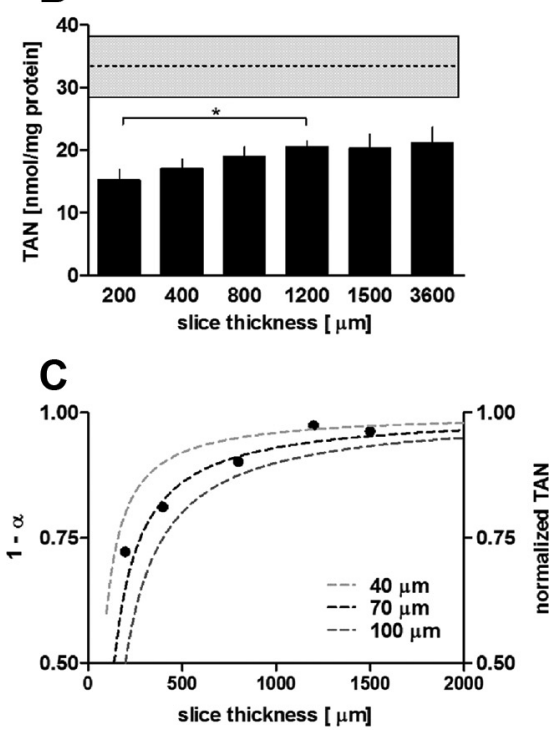

D

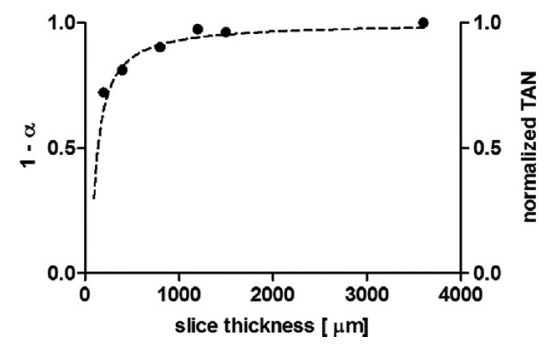

Figure 3. Tissue thickness and handling influences calculation of adenine nucleotide content of brain tissue. $A$, TAN content of whole hippocampus $(n=5)$ and cortex $(n=5)$ immediately after dissection and hippocampal $(n=3)$ and neocortical slices $(n=3)$ immediately after cutting. Note that whole tissue TAN levels are lower than reported in vivo values (dotted black line represents the arithmetic mean $\pm S D$ as shown by the gray area for all reported values from supplemental references, available at www.jneurosci.org as supplemental material), possibly reflecting increased handling/trauma, with only whole cortex approaching in vivo values. B, TAN levels of neocortical/hippocampal slices of varying thickness $(200,400,800,1200,1500$, and $3600 \mu \mathrm{m}$ ) immediately after cutting. All values in $\boldsymbol{A}$ and $\boldsymbol{B}$ are presented as mean \pm SEM; $n=3-8$. C, Theoretical curves ( $Y=1-\alpha$, where $\alpha=d / l$; dotted lines) to estimate the relative contribution of dead cut edges (d) to the total tissue thickness of slices (I, ranging from 100 to $2000 \mu \mathrm{m}$ in $20 \mu \mathrm{m}$ steps), assuming a total thickness for the two dead cut edges of 40 $\mu \mathrm{m}$ (light gray dotted line, $20 \mu \mathrm{m}$ on each side of the slice), $70 \mu \mathrm{m}$ (black dotted line, $35 \mu \mathrm{m}$ on each side of the slice), or $100 \mu \mathrm{m}$ (dark gray dotted line, $50 \mu \mathrm{m}$ on each side of the slice). By normalizing the TAN levels obtained from slices at different thicknesses from $\boldsymbol{B}$ to the TAN values obtained for $3600 \mu \mathrm{m}$ slices (plotted as black dots), we found that these normalized values fit the curve for a total dead cut edge layer of $70 \mu \mathrm{m}$ (black dotted line). $\boldsymbol{D}$, Theoretical curve for the ratio of the thickness of cut dead edges $(d ; 70 \mu \mathrm{m})$ to the tissue thickness $\left(I_{;}\right.$ ranging from 100 to $3600 \mu \mathrm{m}$ in $20 \mu \mathrm{m}$ steps), showing that, with increasing slice thickness, the relative contribution of the thickness of the cut edges decreases, approaching a value of 0.99 (black circles). 
The difference in TAN levels between cortex and hippocampus can also be seen in slices (Fig. 3A). Hippocampal slices had significantly lower TAN levels than cortical slices $(16.4 \pm 1.1$ and $20.7 \pm 0.7 \mathrm{nmol} / \mathrm{mg}$ protein, respectively; $n=3 ; p<0.05$, unpaired $t$ test). These values were $\sim 28 \%$ lower than the respective whole tissue values reported above and $\sim 38 \%$ (cortex) to $50 \%$ (hippocampus) lower than reported in vivo values (Fig. $3 A$ ).

\section{The dead layer on slice surfaces distorts adenine nucleotide measurements}

Empirical observations. To test whether the protein content of dead slice edges (typically 35-50 $\mu \mathrm{m}$ ) (Feig and Lipton, 1990; Siklós et al., 1997; Frenguelli et al., 2003) results in an underestimate of ATP in the viable core of the slice, we prepared neocortical/hippocampal slices of different thickness, thereby changing the ratio of dead to viable tissue. Because there were no significant changes in the TAN levels between slice cutting and $5 \mathrm{~h}$ incubation (Fig. $1 E$ ) (supplemental Table 1, available at www.jneurosci. org as supplemental material) and to bypass the problem of a possible emerging nutrient-deprived core in very thick slices, the analysis was performed immediately after cutting.

The TAN content of slices, relative to the amount of protein, increased $\sim 26 \%$ with increasing thickness from $15.2 \pm 1.7$ $\mathrm{nmol} / \mathrm{mg}$ protein in a $200 \mu \mathrm{m}$ slice to $20.6 \pm 1.0 \mathrm{nmol} / \mathrm{mg}$ protein in a $1200 \mu \mathrm{m}$ slice (Fig. 3B) $(n=5-8 ; p<0.05$, unpaired $t$ test). There was no additional increase in the TAN levels in 1500 $\mu \mathrm{m}$ slices $(20.3 \pm 2.3 \mathrm{nmol} / \mathrm{mg}$ protein; $n=4)$, and we obtained a value of $21.1 \pm 2.6 \mathrm{nmol} / \mathrm{mg}$ protein for $3600 \mu \mathrm{m}$ slices $(n=3)$.

Theoretical predictions. To better understand the dependence of TAN content on slice thickness, we made the assumption that the TAN is proportional to the volume of the tissue $\left(l^{3}\right)$ as defined by a unit of length $l$. If in a slice there is a layer of dead tissue of thickness $d$ devoid of adenine nucleotides at either face of the slice, then the volume of tissue contributing to the TAN is $l^{2}(l-$ $d)$. We further assumed that $d$ is constant and does not depend on slice thickness and expressed $d$ as a proportion of $l(d=\alpha l)$. The volume of tissue contributing to the TAN is thus $l^{3}(1-\alpha)$. If we consider a unit of volume (i.e., $l=1)$, then a plot of $1-\alpha$ against the normalized TAN for different slice thicknesses, assuming constant $d$, should fit our observed data and provide a theoretical estimate of the dead layer of tissue at either face of the slice. In Figure $3 C$, we have plotted theoretical curves for the relative contribution of a dead tissue layer (d) of $20 \mu \mathrm{m}$ (40 $\mu \mathrm{m}$ in total), 35 $\mu \mathrm{m}(70 \mu \mathrm{m}$ in total $)$, and $50 \mu \mathrm{m}(100 \mu \mathrm{m}$ in total $)$ on both slice edges to the total tissue thickness ( $l$, from 100 to $2000 \mu \mathrm{m}$ slices in $20 \mu \mathrm{m}$ steps). By normalizing the measured TAN values in Figure $3 B$ to the TAN value obtained for $3600 \mu \mathrm{m}$ slices $(21.1 \mathrm{nmol} / \mathrm{mg}$ protein) and plotting it on the same graph, we observed a very good fit of our measured values to the theoretical curve obtained for an estimated total dead cut edge layers of $70 \mu \mathrm{m}$, or $35 \mu \mathrm{m}$ for each edge (Fig. $3 C, D$, black dotted lines). We previously reported a value of $35 \mu \mathrm{m}$ as an estimate of the dead slice layer based on histological assessment of $400 \mu \mathrm{m}$ slices (Frenguelli et al., 2003), revealing a remarkable degree of consistency between our experimental observation and our theoretical model.

With this curve (ranging from 100 to $3600 \mu \mathrm{m}$ in $20 \mu \mathrm{m}$ steps) (Fig. 3D), an asymptotic value is approached at a tissue thickness of $3600 \mu \mathrm{m}(1-\alpha=0.980)$, suggesting that the dead cut edges account for only $2 \%$ of the whole tissue thickness. Therefore, assuming a maximal TAN value of $21.1 \mathrm{nmol} / \mathrm{mg}$ protein $(3600$ $\mu \mathrm{m}$ slices) in slices, we might underestimate the TAN content of the viable core tissue in a $400 \mu \mathrm{m}$ slice $(17.1 \pm 1.5 \mathrm{nmol} / \mathrm{mg}$ protein) by $\sim 4 \mathrm{nmol} / \mathrm{mg}$ protein, $\sim 19 \%$. Nonetheless, when cor- rected for this amount, slice TAN levels in $400 \mu \mathrm{m}$ neocortical/ hippocampal slices remain $\sim 37 \%(\sim 12.5 \mathrm{nmol} / \mathrm{mg}$ protein $)$ lower than reported in vivo values $(33.6 \pm 4.7 \mathrm{nmol} / \mathrm{mg}$ protein as shown by the gray area for the mean \pm SD in Fig. $3 B$ ). Hence, this difference is likely attributable to the loss of adenine nucleotides and precursors during the ischemia and physical trauma associated with slice preparation.

\section{Supplementation of aCSF with adenine nucleotide precursors improves cellular ATP levels}

In vivo cerebral TAN or ATP levels recover after brief periods of ischemia (1-5 $\mathrm{min}$ ) to pre-ischemic values after 60-90 min reperfusion (Ljunggren et al., 1974; Kobayashi et al., 1977; Nowak et al., 1985). However, there was no significant increase in TAN levels in slices over a $5 \mathrm{~h}$ incubation period (Fig. $1 E$ ). This might be attributable to a lack of purine precursor metabolites in the aCSF, which might otherwise be used to restore tissue ATP levels via purine salvage or de novo synthesis.

Because two key components of the purine salvage pathway, which is believed to predominate in brain (Gerlach et al., 1971; Mascia et al., 2000; Barsotti and Ipata, 2002), are adenine and D-ribose (Fig. 4A), we tested these compounds in brain slices. Incubating slices in $50 \mu \mathrm{M}$ Ade and $1 \mathrm{~mm}$ Rib resulted in tissue levels of Ade reaching a maximum after $1 \mathrm{~h}$ incubation $(0.92 \pm$ $0.07 \mathrm{nmol} / \mathrm{mg}$ protein), with no additional increase after $3 \mathrm{~h}$ $(0.95 \pm 0.04 \mathrm{nmol} / \mathrm{mg}$ protein; $n=3-5)$ (data not shown). Interestingly, the uptake of Ade was facilitated by $1 \mathrm{~mm}$ Rib (0.56 \pm $0.09 \mathrm{nmol} / \mathrm{mg}$ protein after $3 \mathrm{~h}$ incubation in $50 \mu \mathrm{M}$ Ade alone compared with $0.95 \pm 0.04 \mathrm{nmol} / \mathrm{mg}$ protein after $3 \mathrm{~h}$ incubation in $1 \mathrm{~mm} \mathrm{Rib} / 50 \mu \mathrm{M}$ Ade; $p<0.05$, one-way ANOVA), with no additional increase observed with higher Rib concentrations $(0.83 \pm 0.06 \mathrm{nmol} / \mathrm{mg}$ protein after $3 \mathrm{~h}$ incubation with $10 \mathrm{~mm}$ Rib/50 $\mu$ M Ade, $n=3$ ) (data not shown).

To test whether Ade and Rib could be used by the purine salvage pathway to restore adenine nucleotide levels in brain slices, we incubated freshly cut slices in aCSF supplemented with $1 \mathrm{~mm}$ Rib and $50 \mu \mathrm{m}$ Ade (Fig. 4). The TAN content in slices incubated with Rib/Ade increased to $25.8 \pm 0.7 \mathrm{nmol} / \mathrm{mg}$ protein after $3 \mathrm{~h}$ incubation (compared with $19.1 \pm 1.2 \mathrm{nmol} / \mathrm{mg}$ protein in slices incubated in standard aCSF; $n=3-5 ; p<0.01$, one-way ANOVA) (Fig. $4 B$ ), with ATP accounting for $\sim 92 \%$. When corrected for the influence of the protein content of the dead slice edges ( $\sim 4 \mathrm{nmol} / \mathrm{mg}$ protein) (Fig. $4 B)$, these values $(\sim 30$ $\mathrm{nmol} / \mathrm{mg}$ protein) are close to the values reported for in vivo tissue (33.6 $\pm 4.7 \mathrm{nmol} / \mathrm{mg}$ ) (Fig. $4 B$ ). The elevation of tissue TAN and ATP levels by Rib/Ade did not significantly impact on the EC, which stabilized at $0.96 \pm 0.001$, and the ATP/AMP ratio, which reached an asymptotic value after $3 \mathrm{~h}$ at $141.7 \pm 17.5$ compared with $94.9 \pm 23.5$ for slices incubated in standard aCSF $(n=3-5 ; p>0.05$, one-way ANOVA) (Fig. $4 C)$.

Lower Rib concentrations $(500 \mu \mathrm{M})$ were not as effective in increasing TAN levels and higher Rib concentrations (2.5-10 $\mathrm{mm}$ ) did not further increase the TAN content of slices (data not shown). Furthermore, Ade (50 $\mu \mathrm{M})$ on its own, as well as higher Rib concentrations ( 2.5 or $10 \mathrm{~mm}$ ) on its own did not significantly increase the TAN content in slices (supplemental Table 4, available at www.jneurosci.org as supplemental material). This suggests that both metabolites are needed for effective conversion to adenine nucleotides during a $3 \mathrm{~h}$ incubation period.

To establish whether these elevated levels of TAN and ATP persisted when Rib/Ade was removed, we incubated slices in standard aCSF for $2 \mathrm{~h}$ after $3 \mathrm{~h}$ in Rib/Ade. During this time, tissue adenine content decreased back to baseline $(0.1 \pm 0.05$ 
A

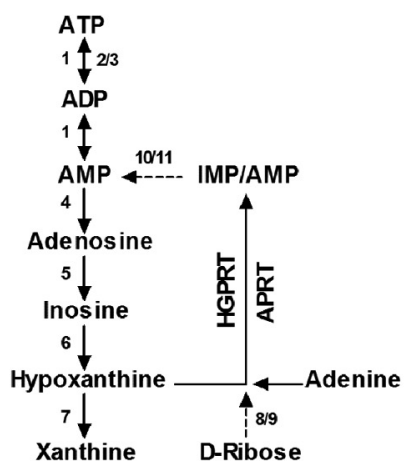

B
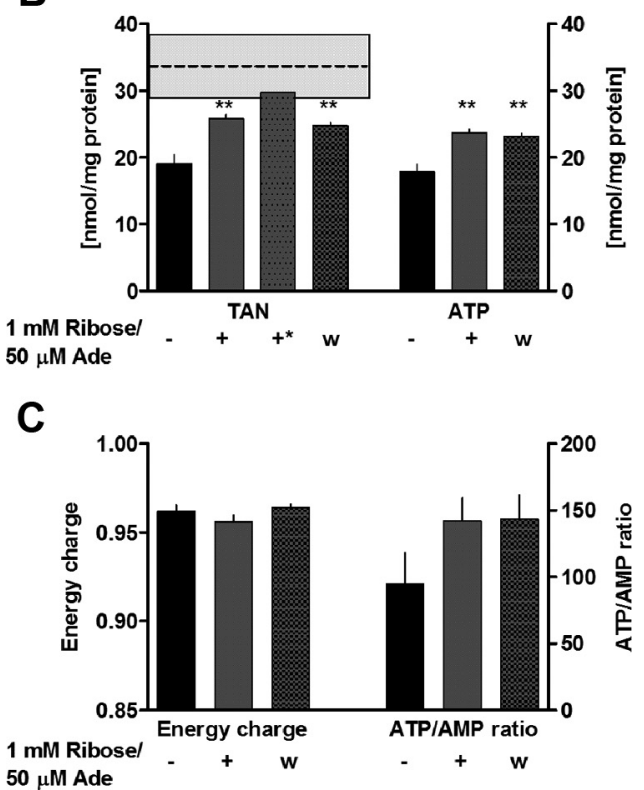

Figure 4. $A$, Degradation of ATP and pathway for Ade and Rib utilization: 1, adenylate kinase; 2, ATPases; 3 , ATP synthase; 4, 5'nucleotidase; 5 , adenosine deaminase; 6 , purine nucleoside phosphorylase; 7 , xanthine oxidase; 8 , ribokinase; 9 , phosphoribosylpyrophosphate synthetase; 10 , adenylosuccinate synthetase; 11 , adenylosuccinate lyase. APRT, Adenine phosphoribosyltransferase; HGPRT, hypoxanthine phosphoribosyltransferase. Solid lines indicate direct routes, and dashed lines indicate indirect routes. The reactions of the purine salvage pathway are catalyzed by HGPRT and APRT. B, Improved recovery of TAN (left $y$-axis) and ATP (right $y$-axis) levels in slices after $3 \mathrm{~h}$ incubation in standard aCSF $(-$, black bars) or aCSF supplemented with $1 \mathrm{~mm}$ D-ribose $/ 50 \mu \mathrm{m}$ adenine (+, gray bars). Under these conditions and with the correction for dead tissue on the edge of slices $(\sim 4 \mathrm{nmol} / \mathrm{mg}$ protein), slice TAN levels $(+*$, dashed gray bar) are close to those reported in vivo (dotted black line represents the arithmetic mean $\pm S D$ as shown by the gray area for all reported values from supplemental references, available at www.jneurosci.org as supplemental material). Elevated TAN levels are maintained when ribose/adenine are washed out $(\mathrm{w})$ of the tissue (hatched gray bars) by transferring the slices to standard aCSF for $2 \mathrm{~h}$. C, Energy charge (lefty-axis) and ATP/AMP levels (right $y$-axis) are not significantly different in slices after $3 \mathrm{~h}$ incubation in standard aCSF (-, black bars), in aCSF supplemented with $1 \mathrm{~mm}$ D-ribose/50 $\mu$ m adenine ( + , gray bars) or after washout ( $\mathrm{w}$ ) of ribose/adenine (hatched gray bars) by transferring the slices to standard aCSF for $2 \mathrm{~h}$. All values are presented as mean $\pm \mathrm{SEM} ; n=3-5 .{ }^{* *} p<0.01$ compared with slices incubated in standard aCSF, one-way ANOVA with Bonferroni's multiple comparison test. When no error bars can be seen, they are smaller than the symbol.

nmol/mg protein; $n=3$ ) (data not shown). However, the higher TAN levels were maintained even when Rib and Ade were washed out of the slices (Fig. 4B) (supplemental Table 4, available at www.jneurosci.org as supplemental material) (24.9 \pm 0.4 $\mathrm{nmol} / \mathrm{mg}$ protein; $n=3 ; p<0.01$ compared with standard slices, one-way ANOVA), as were the energy charge and ATP/AMP ratio (Fig. 4C).
These data suggest that the full recovery of slice ATP levels is limited by the lack of ATP precursors in the aCSF. In addition, these data also indicate that providing ATP precursors in the form of Rib/Ade allows the viable core of brain slices to restore ATP levels to values close to those reported in vivo.

Electrophysiological properties of slices incubated in Rib/Ade To establish whether the higher ATP and TAN levels in slices incubated in Rib/Ade would alter the electrophysiological properties of brain slices, we performed extracellular recordings from the CA1 region of hippocampal slices. Input-output curves, paired-pulse facilitation, and LTP were compared between slices incubated for $3-8 \mathrm{~h}$ in standard aCSF and slices incubated for $2 \mathrm{~h}$ in $1 \mathrm{~mm}$ Rib and $50 \mu \mathrm{m}$ Ade then for $1-6 \mathrm{~h}$ in standard aCSF to wash these agents out of the tissue. A $2 \mathrm{~h}$ incubation period in Rib/Ade was chosen, because slice TAN levels reached an asymptotic value at that time $(25.4 \pm 2.3 \mathrm{nmol} / \mathrm{mg}$ protein $)$, with no additional increase after $3 \mathrm{~h}(25.8 \pm 0.6 \mathrm{nmol} / \mathrm{mg}$ protein; $n=$ 3-5) (data not shown).

Basal synaptic transmission is normal in Rib/Ade-treated slices The recovery of synaptic transmission after slice cutting was not different between standard and Rib/Ade-treated slices (supplemental Fig. 2, available at www.jneurosci.org as supplemental material). Furthermore, in a separate series of slices, there was no significant difference in input-output curves (Fig. $5 A ; n=15$ 16) and paired-pulse ratios (Fig. $5 B ; n=18-22$ ) between the two set of slices ( $p>0.05$, one-way ANOVA). Likewise, $50 \mu \mathrm{m}$ Ade on its own (Fig. $5 C ; n=4$ ) or in combination with $1 \mathrm{~mm}$ Rib (Fig. $5 D ; n=6$ ) did not change paired-pulse ratios when acutely applied to slices. This suggests that, under conditions of lowfrequency stimulation of afferent fibers, the enhanced tissue ATP levels in Rib/Ade-treated slices is not being released to form adenosine in the extracellular space, which would, via inhibitory $A_{1}$ Rs, inhibit glutamate release and raise the paired-pulse facilitation ratio. These negative results suggest that the activation $A_{1}$ Rs and basal handling of adenosine is normal between standard and Rib/ Ade-treated slices. To test this directly, we applied the selective $\mathrm{A}_{1} \mathrm{R}$ agonist $N^{6}$-CPA (10 nM) (Gadalla et al., 2004) or the adenosine uptake inhibitors NBTI $(5 \mu \mathrm{M}) / \mathrm{DIPY}(10 \mu \mathrm{M})$ (Frenguelli et al., 2007; Etherington et al., 2009) to both sets of slices (Fig. $5 E, F)$. The concentrations chosen were submaximal for complete depression of the fEPSP to avoid a "floor effect" obscuring potential differences between the two sets of slices. Furthermore, we have shown previously that NBTI/DIPY causes a depression of the fEPSP that can be reversed with $A_{1} R$ antagonists (Pearson et al., 2001) and have demonstrated the increase in extracellular adenosine directly with adenosine biosensors (Frenguelli et al., 2007; Etherington et al., 2009).

The rate and extent of fEPSP depression after a $15 \mathrm{~min}$ application of $N^{6}$-CPA was the same in control $(50.0 \pm 1.6 \% ; n=5)$ and Rib/Ade-treated ( $50.4 \pm 1.6 \% ; n=5 ; p>0.05$, unpaired $t$ test) slices (Fig. 5E). Likewise, the application NBTI/DIPY for 40 min resulted in the same rate and amount of depression in both sets of slices ( $40 \pm 5.9 \%$ for standard slices; $43 \pm 3.3 \%$ for Rib/ Ade treated slices; $n=4 ; p>0.05$, unpaired $t$ test) (Fig. 5F). These data suggest that Rib/Ade pretreatment does not influence the sensitivity of the $A_{1} R$ to agonists, nor is the activity of equilibrative adenosine transporters affected.

Furthermore, the fact that acute application of Ade did not change paired-pulse ratios (Fig. 5C,D), shows that the recently described $\mathrm{G} \alpha_{\mathrm{i}}$-protein-coupled adenine receptor (Bender et al., 2002; von Kügelgen et al., 2008), if present in the hippocampus, 
does not have any presynaptic effects on neurotransmitter release. However, to further exclude the possibility of differences in cAMP formation between Rib/ Ade-treated slices and slices incubated in standard aCSF, we applied $50 \mu \mathrm{m}$ forskolin to both sets of slices and compared the increase in fEPSP slopes (Fig. 5G,H). There was no significant difference in forskolin-induced potentiation between Rib/Ade-treated slices and slices incubated in standard aCSF (Fig. 5G) (147.4 \pm $9.8 \%$ in standard slices and $159.1 \pm 12.9 \%$ in Rib/Ade-treated slices; $n=3-4$; $p<$ 0.05 compared with baseline before application of forskolin, $p>0.05$ between standard slices and Rib/Ade-treated slices at $20 \mathrm{~min}$ after application of forskolin, oneway ANOVA). Paired-pulse facilitation (50 ms interpulse interval) was similarly affected by forskolin in standard slices and Rib/Ade-treated slices (Fig. $5 H)(n=$ $3-4 ; p>0.05$ between standard slices and Rib/Ade-treated slices, unpaired $t$ test). This suggests that adenylyl cyclase activation and cAMP production is not impaired in Rib/Ade-treated slices.

Long-term potentiation is impaired in Rib/Ade-treated slices

Slices incubated in standard aCSF showed robust LTP 55-60 min after tetanic stimulation (one train of 100 shocks at $100 \mathrm{~Hz}$; $135 \pm 5.8 \%$ of baseline; $n=9 ; p<0.001$ compared with $5 \mathrm{~min}$ baseline before tetanic stimulation, one-way ANOVA) (Fig. $6 A$ ). However, LTP in slices incubated for $2 \mathrm{~h}$ in $1 \mathrm{~mm}$ Rib and $50 \mu \mathrm{M}$ Ade decayed back to baseline $60 \mathrm{~min}$ after tetanic stimulation (108 $\pm 4.9 \%$ of baseline; $n=11$; $p>0.05$ compared with $5 \mathrm{~min}$ baseline before tetanic stimulation, one-way ANOVA) and was significantly lower in amplitude than LTP in control slices incubated in standard aCSF $(p<0.001$ from 55 to $60 \mathrm{~min}$ after LTP induction, one-way ANOVA). Stable recordings could be achieved in Rib/ Ade-treated slices over the same time period $(94 \pm 6.6 \%$ of baseline at $75 \mathrm{~min} ; n=3$ ) (data not shown), which argues against baseline drift as being the cause for the observed decay in LTP. In contrast, acute application of Ade or Rib alone, or in combination, did not impair tetanusinduced LTP $(133 \pm 5 \%$ of baseline for standard slices, $131 \pm 13 \%$ after acute application of $50 \mu \mathrm{m}$ Ade, $140 \pm 9 \%$ after acute application of $1 \mathrm{~mm}$ Rib, and $131 \pm 8 \%$ after acute application of $1 \mathrm{~mm}$ Rib/50 $\mu \mathrm{M}$ Ade at 60 min after LTP induction; $n=4-5$ ) (data not shown), implying a requirement for uptake and intracellular conversion to adenine nucleotides.
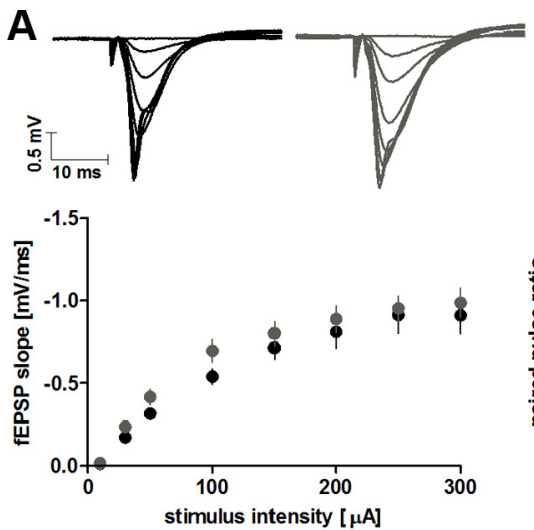

C
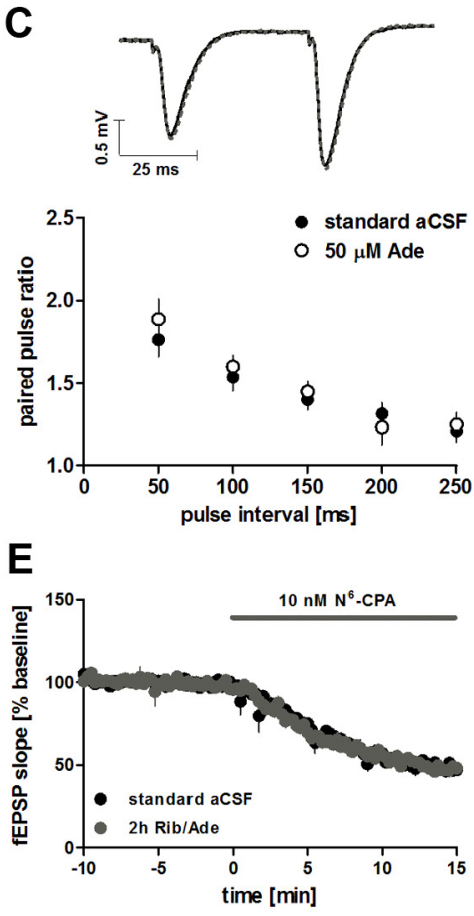

G

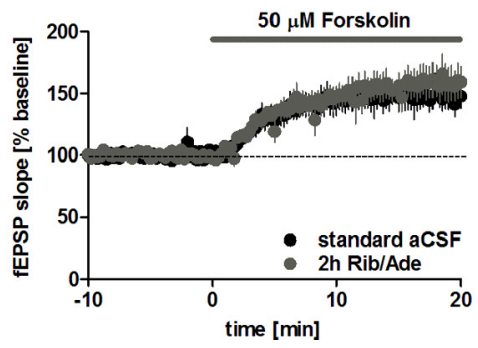

B
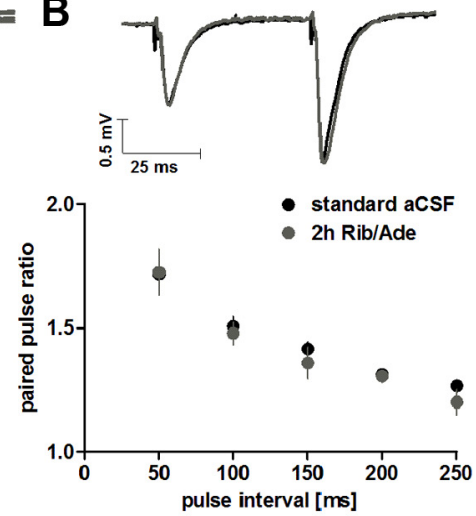

D
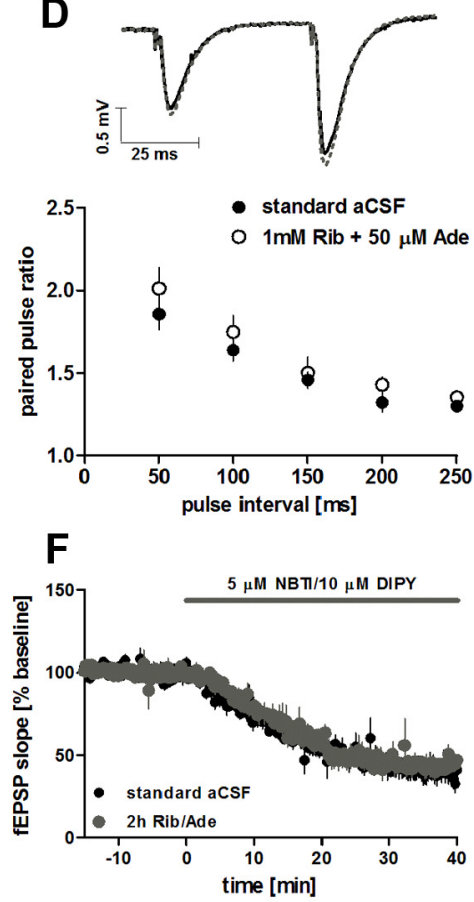

$\mathrm{H}$

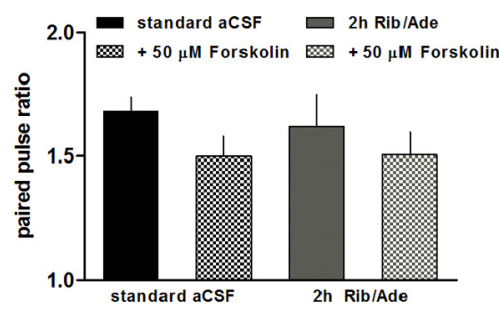

Figure 5. Basal synaptic transmission, adenosine $A_{1}$ receptor activation, and adenosine uptake are not different between slices incubated in standard aCSF and slices treated for $2 \mathrm{~h}$ i $1 \mathrm{~mm}$ Rib and $50 \mu \mathrm{m}$ Ade. Input- output curves $(n=15-16)(\boldsymbol{A})$ and paired-pulse ratios $(n=18-22)(B)$ for slices incubated in standard aCSF (black circles) and slices treated for $2 \mathrm{~h}$ with Rib/Ade-supplemented aCSF (gray circles). Insets are representative fEPSPs from $10-300 \mu \mathrm{A}(\boldsymbol{A})$ and at $50 \mathrm{~ms}$ interpulse interval ( $\boldsymbol{B})$ for controls and Rib/Ade-treated slices. C, D, Paired-pulse ratios for slices incubated in standard aCSF before (black circles) and after acute application of $50 \mu \mathrm{m}$ Ade (C, white circles, $n=4$ ) or $50 \mu$ Ade and $1 \mathrm{~mm}$ Rib ( $\boldsymbol{D}$, white circles, $n=6$ ). Insets are representative fEPSPs at 50 ms interpulseinterval before (black traces) and after application of Ade or Rib/Ade (dotted gray traces). There was no difference in the rate or magnitude of fEPSP depression in response to the selective $A_{1}$ Ragonist $N^{6}-\mathrm{CPA}(10 \mathrm{~nm} ; n=5)(E)$ or the combination of the adenosine uptake inhibitors NBTI $(5 \mu \mathrm{m}) / \mathrm{DIPY}(10$ $\mu \mathrm{m} ; n=4)$ in standard slices or Rib/Ade-treated slices $(\boldsymbol{F})$. G, Forskolin-induced potentiation in standard slices (black circles) and Rib/Adetreated slices (gray circles). Forskolin at $50 \mu \mathrm{m}$ was applied to slices for $20 \mathrm{~min}$ and no differences were observed in the amount of potentiation (147.4 $\pm 9.8 \%$ in standard slices and $159.1 \pm 12.9 \%$ in Rib/Ade treated slices; $n=3-4)$ or the decrease in paired-pulse facilitation $(n=3-4)(\boldsymbol{H})$. Recordings were performed at $33.4 \pm 0.2^{\circ} \mathrm{C}$ at a flow rate of $7-8 \mathrm{ml} / \mathrm{min}$ after a $\geq 3 \mathrm{~h}$ recovery period from slice cutting. All values are presented as mean \pm SEM. No significant differences observed between standard and Rib/Ade-treated slices with unpaired $t$ tests or one-way ANOVA with Bonferroni's multiple comparison test. When no error bars can be seen, they are smaller than the symbol. 
A
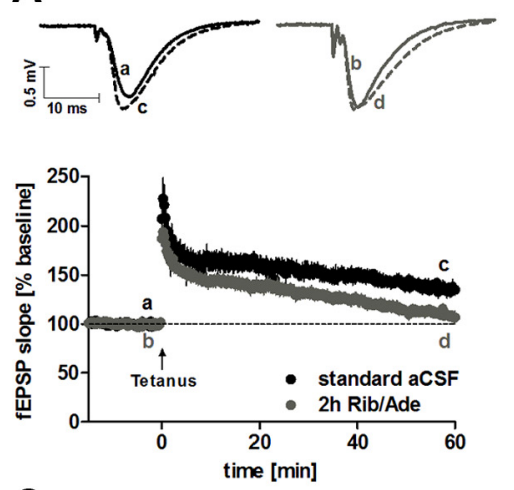

C
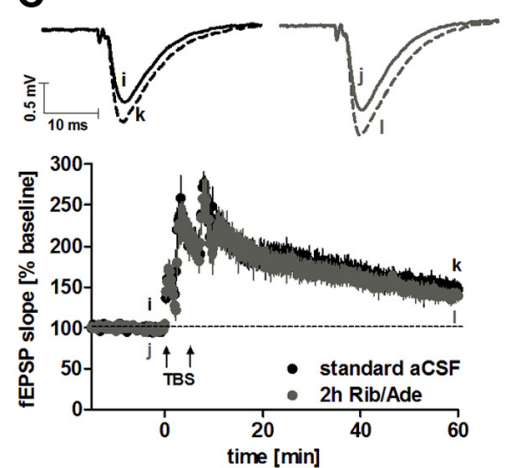

E
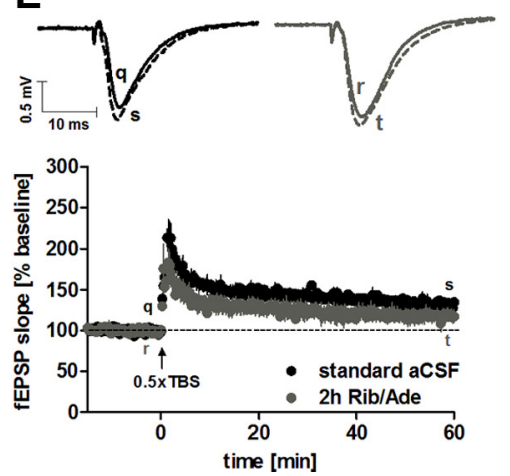

B

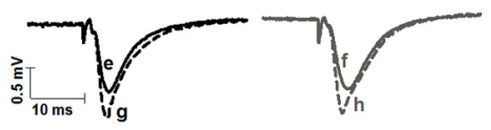

8-CPT

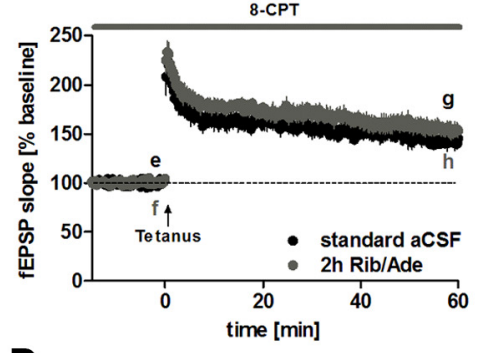

D
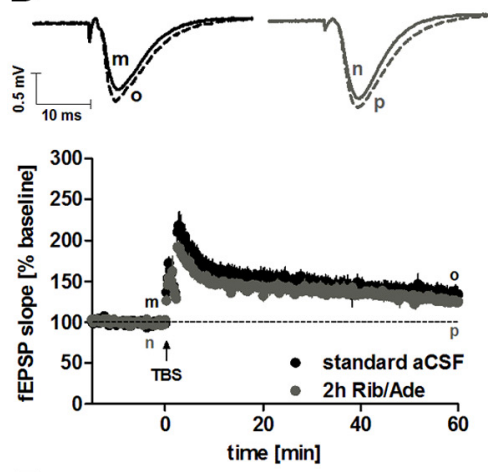

$\mathbf{F}$

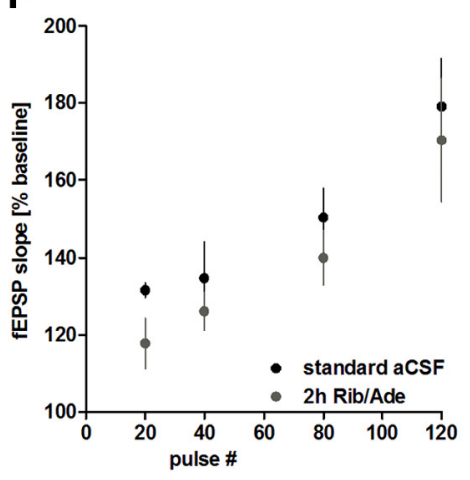

Figure 6. LTP induction with tetanic stimulation is impaired in slices treated for $2 \mathrm{~h}$ in $1 \mathrm{~mm}$ Rib and $50 \mu \mathrm{m}$ Ade in an $\mathrm{A}_{1}$ R-dependent manner. $\boldsymbol{A}$, LTP after tetanic stimulation $(1 \times 100$ stimuli at $100 \mathrm{~Hz})$ in slices incubated for $2 \mathrm{~h}$ in Rib/Adesupplemented aCSF (gray circles; $n=11$ ) and slices incubated in standard aCSF (black circles; $n=9$ ). $\boldsymbol{B}$, LTP after tetanic stimulation and in the presence of 8-CPT in slices incubated for $2 \mathrm{~h}$ in Rib/Ade-supplemented aCSF (gray circles; $n=6$ ) and slices incubated in standard aCSF (black circles; $n=5) . C, D$, LTP is not different in slices incubated for $2 \mathrm{~h}$ in Rib/Ade-supplemented aCSF (gray circles) and standard aCSF (black circles) when either two (C; 5 min apart; 80 pulses; $n=6-7$ ) or one ( $\boldsymbol{D} ; 40$ pulses; $n=6$ for both) TBS are delivered (TBS: 10 trains of 4 pulses at $100 \mathrm{~Hz}, 200 \mathrm{~ms}$ interval). $\boldsymbol{E}$, In contrast, a briefer TBS ( 5 trains, 20 pulses) resulted in significant LTP in standard slices 55-60 min after TBS (black circles; $n=3$ from 2 animals) but not Rib/Ade-treated slices (gray circles; $n=4$ from 3 animals). F, Plot of pulse number versus magnitude of LTP $55-60$ min (20,40,80 pulses) or 30 min (120 pulses) after induction in standard and Rib/Ade-treated slices. Note that, throughout the pulse number range, Rib/Adetreated slices give rise to lower LTP, which falls below significant LTP induction threshold at 20 pulses. Data for 120 pulses from Figure 7 with 120 pulses delivered via $3 \times 40$ pulse theta trains at 10 s intervals with LTP measured after 30 min. All insets are representative of fEPSPs before (solid lines) and $60 \mathrm{~min}$ after the induction of LTP (dashed lines). Recordings were performed at $33.4 \pm 0.2^{\circ} \mathrm{C}$ at a flow rate of $7-8 \mathrm{ml} / \mathrm{min}$ after a $\geq 3 \mathrm{~h}$ recovery period from slice cutting. All values are presented as mean \pm SEM.

A potential reason for the impaired LTP stabilization in Rib/ Ade-treated slices might be that, because of the higher TAN pool, enhanced synaptic activity during tetanic stimulation causes the activity-dependent release of ATP and/or its metabolite adenosine. To test this, we incubated slices in the ATP $\mathrm{P}_{2}$ receptor antagonist PPADS $(10 \mu \mathrm{M})$ and $\mathrm{A}_{1} \mathrm{R}$ antagonist 8-CPT $(1 \mu \mathrm{M})$ before the induction of LTP. Preincubation with PPADS did not prevent the decay of LTP in Rib/Ade-treated slices (108 $\pm 15 \%$ of baseline 60 min after LTP induction; $n=$ 4) (data not shown). These observations suggest that, if ATP is being released during tetanic stimulation, it is not directly responsible via $\mathrm{P}_{2}$ receptors for the impairment of LTP.

To test for a role for adenosine $A_{1}$ receptors, we applied 8-CPT (1 $\mu \mathrm{M})$, a selective $A_{1} R$ antagonist, to slices that had either been pretreated with Rib/Ade or incubated in standard aCSF. Ten minutes after acute application of 8-CPT, fEPSPs had increased to $121.4 \pm 0.7 \%$ in standard slices $(n=6)$ (data not shown) and to $124.1 \pm 0.5 \%$ in Rib/Ade-treated slices $(n=8)$ (data not shown) and was associated with a similar decrease in PPF in both (data not shown). Both these changes in synaptic transmission are indicative of the removal of a basal adenosine $A_{1} R$ dependent inhibitory tone. The fact that the changes were similar between the two conditions argues against the possibility of an increased basal adenosine tone in Rib/Ade-treated slices. This is consistent with the following observations: (1) similar tissue adenosine levels in both sets of slices after a $3 \mathrm{~h}$ incubation (standard slices, $0.05 \pm 0.004 \mathrm{nmol} / \mathrm{mg}$ protein, $n=$ 3; Rib/Ade-treated slices, $0.04 \pm 0.002$; $n=3 ; p>0.05$, unpaired $t$ test) (data not shown), (2) normal basal transmission and paired-pulse facilitation in Rib/Adetreated slices (Fig. $5 A-D$ ), (3) identical effects of $A_{1} R$ activation and uptake inhibition (Fig. $5 E, F$ ), and (4) equal effects of forskolin (Fig. 5G,H).

Having established that the basal handling and effects of adenosine were similar in control and Rib/Ade-treated slices, we next examined the effect of the $A_{1} R$ antagonist on tetanus-induced LTP with or without previous treatment with Rib/Ade. LTP was induced when a stable fEPSP baseline of $15 \mathrm{~min}$ was collected, $\sim 30-40$ min after application of 8-CPT. Both sets of slices showed robust LTP in the presence of 8-CPT 55-60 min after tetanic stimulation (Fig. 6B) $(143 \pm 6.0 \%$ in standard slices and $154 \pm 6.7 \%$ in Rib/ Ade-treated slices; $n=5-6 ; p<0.001$ compared with 5 min baseline before tetanic stimulation, $p>0.05$ between standard slices and Rib/Ade-treated slices 55-60 min after tetanic stimulation, oneway ANOVA). This suggests that the activity-dependent release of adenosine contributes to the impairment of LTP induction in Rib/Ade-treated slices.

We hypothesized that this deficit in LTP induction represented a raising of the threshold for LTP by the activitydependent accumulation of extracellular adenosine and activation of inhibitory $A_{1}$ Rs. This hypothesis predicted that stronger activation of postsynaptic neurons should overcome 
this threshold. Accordingly, we used a TBS LTP induction protocol (Larson et al., 1986), which is known to deliver sustained glutamatergic excitation while causing fatigue of GABAmediated inhibition and hence greater activation of NMDA receptors (Chen et al., 2010).

Control and Rib/Ade-treated slices were stimulated with two TBS at 5 min intervals $(2 \times 10$ trains of four pulses at $100 \mathrm{~Hz}$ with $200 \mathrm{~ms}$ intervals, i.e., 80 pulses in total). This protocol resulted in robust LTP in both standard and Rib/Ade-treated slices 55-60 min after TBS (Fig. 6C) (150.2 $\pm 7.6 \%$ in standard slices and $140.0 \pm 7.1 \%$ in Rib/Ade-treated slices; $n=6-7 ; p<0.001$ compared with $5 \mathrm{~min}$ baseline before TBS, $p>0.05$ between standard slices and Rib/Ade-treated slices at 55-60 min after TBS, one-way ANOVA). One TBS (40 pulses) resulted in smaller LTP 55-60 min after TBS and showed little difference between standard and Rib/Ade-treated slices (Fig. 6D) (137.7 $\pm 9.5 \%$ in standard slices and $126.2 \pm 5.0 \%$ in Rib/Ade-treated slices; $n=6$; $p<0.01$ for standard slices and $p<0.05$ for Rib/Ade-treated slices compared with $5 \mathrm{~min}$ baseline before TBS, $p>0.05$ between standard slices and Rib/Ade-treated slices at 55-60 min after TBS, one-way ANOVA).

To confirm that TBS resulted in greater depolarization compared with tetanic stimulation, we measured the area associated with each pulse induced by tetanic stimulation (100 pulses) and TBS (40 pulses) in a manner similar to that described recently (Chen et al., 2010). A comparison of the normalized cumulative area evoked by each pulse in a tetanus and TBS (supplemental Fig. $3 A$, available at www.jneurosci.org as supplemental material) revealed a dramatic difference between the two: in a tetanus, most of the depolarization had occurred within the first 20 pulses, whereas during TBS, the depolarization increased almost linearly during the 40 pulse train.

Furthermore, during a tetanus, there was evidence of an influence of Rib/Ade in causing fatigue of transmission during the later stages of the train ( $>20$ pulses) (supplemental Fig. $3 A$, available at www.jneurosci.org as supplemental material). This was prevented in slices treated with 8-CPT (supplemental Fig. 3B, available at www.jneurosci.org as supplemental material) and is consistent with a gradual synaptic accumulation of adenosine. Indeed, the apparent enhancement in 8 -CPT/Rib/Ade-treated slices may reflect an action of adenosine on facilitatory adenosine $\mathrm{A}_{2}$ (Kessey and Mogul, 1998; Fujii et al., 1999; Almeida et al., 2003) or $A_{3}$ (Costenla et al., 2001) receptors. In contrast, this Rib/Ade-induced fatigue was hardly present during one TBS (supplemental Fig. 3A, available at www.jneurosci.org as supplemental material), two TBS given 5 min apart (supplemental Fig. $3 C$, available at www.jneurosci.org as supplemental material), or three TBS given $10 \mathrm{~s}$ apart (supplemental Fig. $3 D, E$, available at www.jneurosci.org as supplemental material), suggesting rapid clearance of adenosine in the $200 \mathrm{~ms}$ between each $4 \times 100 \mathrm{~Hz}$ stimuli.

An examination of the cumulative depolarization evoked by tetanic stimulation (supplemental Fig. $3 A$, available at www. jneurosci.org as supplemental material) predicted that $\sim 20$ pulses was the threshold for Rib/Ade to inhibit the induction of TBS LTP: this was the point at which cumulative tetanic depolarizations diverged when Rib/Ade was present and also equivalent to the number of TBS pulses required to evoke the maximal tetanic depolarization in Rib/Ade. Accordingly, delivery of 20 TBS pulses $(5 \times 4$ pulses at $100 \mathrm{~Hz}, 200 \mathrm{~ms}$ apart $)$ resulted in significant LTP in standard slices but not in Rib/Ade-treated slices 55-60 min after TBS (Fig. 6E) (131.6 $\pm 2 \%$ in standard slices and $117.8 \pm 6.6 \%$ in Rib/Ade-treated slices; $n=3-4 ; p<0.01$ for standard slices and $p>0.05$ for Rib/Ade-treated slices compared with 5 min baseline before TBS, one-way ANOVA). A comparison of the magnitude of LTP versus the number of TBS pulses (Fig. $6 F$ ) reveals a consistent inhibitory influence of Rib/Ade treatment on the magnitude of LTP.

These data point to the release of either ATP or adenosine during electrical stimulation, which, via adenosine $A_{1}$ Rs, inhibits the induction of LTP in response to tetanic stimulation in Rib/ Ade-treated slices. Importantly, this impairment can be overcome by additional stimulation, suggesting that the elevated levels of tissue ATP translate into raising the threshold for LTP induction.

\section{Real-time measurement of adenosine release during LTP induction}

To further test whether the higher TAN levels in Rib/Ade-treated slices resulted in a greater accumulation of adenosine during periods of electrical stimulation of afferent fibers, we used adenosine biosensors (Frenguelli et al., 2003) to measure the real-time release of adenosine during TBS and LTP induction. The sensors (adenosine and null sensors) were placed in stratum radiatum of the CA1 region of hippocampal slices between the recording and stimulating electrodes.

We could not detect any measurable release of adenosine during tetanic stimulation $(100 \mathrm{~Hz}, 1 \mathrm{~s})$ or consistently with one TBS (data not shown), presumably because the released adenosine is below the limit of detection for adenosine biosensors (50 nM) or because the released adenosine remained close to the site of release and was not available for detection by the sensor. For this reason, we used a more intense protocol that would be more likely to result in greater adenosine release and sufficient spillover of adenosine to be detected by the sensors. Accordingly, with a multiple TBS protocol (10 trains of four pulses at $100 \mathrm{~Hz}, 200 \mathrm{~ms}$ apart, repeated three times at $10 \mathrm{~s}$ intervals) (Fig. $7 A$ ), we were able to detect a rise in extracellular adenosine in slices incubated in standard aCSF and slices treated with Rib/Ade (Fig. 7B).

Rib/Ade-treated slices released significantly more adenosine during TBS as measured by integrating the area under the adenosine signal at the start of TBS to 5 min after stimulation (Fig. $7 B$ ) $\left(0.64 \pm 0.1 \mu \mathrm{M}^{\prime *} \mathrm{~min}\right.$ in slices incubated in standard aCSF and $1.98 \pm 0.1 \mu \mathrm{M}^{\prime *} \mathrm{~min}$ in Rib/Ade-treated slices; $n=3 ; p<0.01$, unpaired $t$ test). Despite this greater release of adenosine, we could not observe any differences in LTP (Fig. 7A) between the two sets of slices as measured at $30 \mathrm{~min}$ after TBS. This is likely attributable to the fact that the strong stimulation protocol (Fig. $6 C, D)$ overcame the inhibitory effects of $A_{1} R$.

These results suggest that higher intracellular TAN or ATP levels result in increased activity-dependent adenosine release during periods of strong electrical stimulation, which can modulate the induction threshold for LTP.

\section{Mechanism of activity-dependent adenosine release}

To establish whether the released adenosine arose from direct release of adenosine or from extracellular degradation of ATP, we used adenosine uptake inhibitors (NBTI/DIPY) and POM-1, a noncompetitive inhibitor of ectonucleotidases (Müller et al., 2006; Wall et al., 2008). To assess the effect of these drugs on adenosine release, TBS-induced adenosine release was evoked twice (45-60 min apart): the first TBS was in control aCSF (in either standard slices or Rib/Ade-treated slices), and the second was in the presence of NBTI $(5 \mu \mathrm{M}) / \mathrm{DIPY}(10 \mu \mathrm{M})$ or POM-1 $(100 \mu \mathrm{M})$, which were applied $30 \mathrm{~min}$ after the initial TBS. Repeating TBS twice within 45-60 min did not affect adenosine 

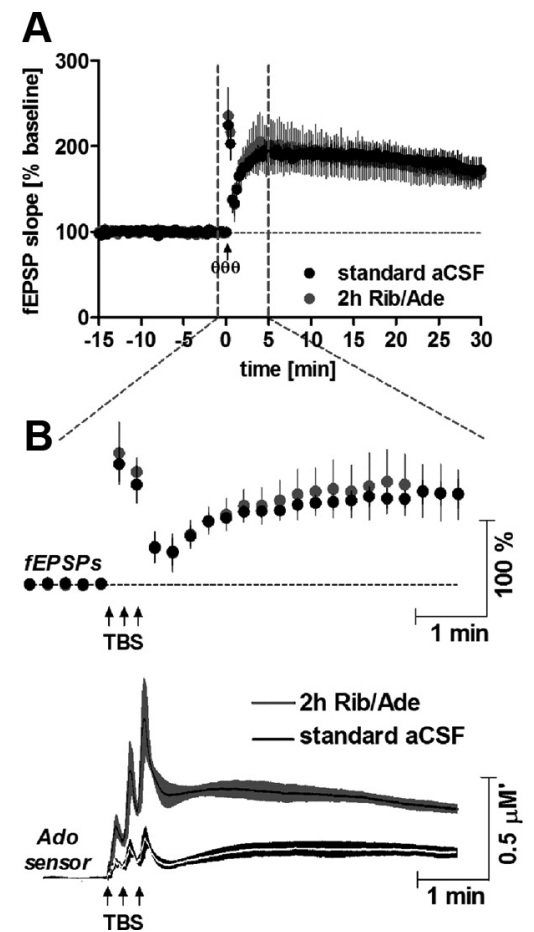

Figure 7. Real-time measurement of adenosine release during LTP induction reveals significantly higher adenosine release in slices treated for $2 \mathrm{~h}$ in $1 \mathrm{~mm}$ Rib and $50 \mu \mathrm{m}$ Ade. $A$, fEPSP slopes after LTP induction with TBS (10 trains of 4 pulses, at $100 \mathrm{~Hz} 200 \mathrm{~ms}$ apart, applied 3 times with 10 s intervals) are not different in slices incubated for $2 \mathrm{~h}$ in Rib/Ade-supplemented aCSF (gray circles; $n=4$ ) and slices incubated in standard aCSF (black dots; $n=5$ ). $\boldsymbol{B}$, fEPSP slopes and adenosine sensor traces from $1 \mathrm{~min}$ before and $5 \mathrm{~min}$ after TBS, as shown by the gray dotted lines in $\boldsymbol{A}$. Adenosine sensor traces show pooled traces of all experiments for standard slices (white line with black area for mean $\pm \mathrm{SEM}$, respectively; $n=3$ ) and Rib/Ade-treated slices (black line with gray area for mean $\pm S E M$, respectively; $n=3$ ). Adenosine sensors placed between the recording and stimulating electrodes show significantly higher adenosine release in Rib/Ade-treated slices during LTP induction. All values are presented as mean \pm SEM.

release (supplemental Fig. $4 A$, available at www.jneurosci.org as supplemental material). If adenosine was released directly, we would expect the transport inhibitors to reduce TBS-induced adenosine accumulation as they represent a major efflux pathway for adenosine into the extracellular space (Baldwin et al., 2004). If extracellular adenosine arose from the metabolism of ATP, POM-1 should reduce TBS-induced adenosine release.

The effectiveness of POM-1 to inhibit ATP breakdown in hippocampal brain slices was assessed by inserting adenosine biosensors into slices and measuring adenosine production after exogenous ATP application in the presence and absence of POM-1 (Wall et al., 2008). POM-1 caused a time-dependent inhibition of ATP breakdown: in the absence of POM-1, $50 \mu \mathrm{M}$ ATP yielded $3.5 \pm 0.2 \mu \mathrm{M}^{\prime}$ adenosine. After application of POM-1 for $5 \mathrm{~min}$, ATP breakdown was inhibited by $30 \pm 3 \%$ $\left(2.5 \pm 0.1 \mu \mathrm{M}^{\prime} ; n=3 ; p>0.05\right.$ compared with initial response, one-way ANOVA), whereas after $15 \mathrm{~min}$, the metabolism of ATP was inhibited by $42 \pm 2 \%\left(2 \pm 0.2 \mu \mathrm{M}^{\prime} ; n=3 ; p<0.05\right.$ compared with initial response, one-way ANOVA) (supplemental Fig. $4 B, C$, available at www.jneurosci.org as supplemental material). We therefore decided to wait $15 \mathrm{~min}$ after POM-1 application to study the effect of POM-1 on TBS-induced adenosine release.

In the presence of POM-1, TBS-induced adenosine release was variable but showed no evidence of inhibition of adenosine release. In fact, the reverse was observed: POM-1 seemed to increase TBS-induced adenosine release in both standard and Rib/
Ade slices (supplemental Fig. 4A, available at www.jneurosci.org as supplemental material). This could represent an off-target effect, as we have suggested exist in the use of POM-1 (Wall et al., 2008), or could reflect a previously described ATP-mediated facilitation of adenosine release via the activation of ATP $\mathrm{P}_{2}$ receptors (Almeida et al., 2003). To address this, we incubated Rib/ Ade-treated slices with the $\mathrm{P}_{2}$ antagonist PPADS (10 $\left.\mu \mathrm{M}\right)$ for 10 min before TBS. PPADS had no significant effect on adenosine release in Rib/Ade-treated slices $\left(2.0 \pm 0.41 \mu \mathrm{M}^{\prime *}\right.$ min for Rib/ Ade-treated slices; $n=10$; and $2.0 \pm 0.61 \mu \mathrm{M}^{\prime \star} \mathrm{min}$ for Rib/Adetreated slices in the presence of PPADS; $n=3 ; p>0.05$, unpaired $t$ test, ) and indeed did not affect the increased TBS-induced adenosine release in the presence of POM-1 $\left(2.8 \pm 0.45 \mu \mathrm{M}^{\prime *} \min\right.$ for Rib/Ade-treated slices after POM-1 application; $n=4$; and 2.3 and $3.3 \mu \mathrm{M}^{\prime \star}$ min in two Rib/Ade-treated slices in the presence of POM-1 and PPADS) (supplemental Fig. $4 A$, available at www. jneurosci.org as supplemental material). These negative results with the ectonucleotidase inhibitor POM-1 argue against an appreciable release of ATP and extracellular conversion to adenosine.

In contrast, application of NBTI/DIPY for 30 min resulted in a 50\% reduction in TBS-induced adenosine release in both sets of slices (supplemental Fig. $4 A$, available at www.jneurosci.org as supplemental material) $(50.3 \pm 17.0 \%$ for control slices, $n=4$, $p=0.06 ; 49.2 \pm 11.0 \%$ for Rib/Ade-treated slices, $n=3, p=$ 0.04 , paired $t$ test), suggesting a role of equilibrative adenosine transporters in the release of adenosine in response to highfrequency stimulation of afferent fibers.

\section{Discussion}

Despite the importance and widespread use of brain slices as models of the mammalian CNS, criticisms remain regarding their metabolic integrity. Our aim was to address this issue to study (1) the energetic recovery of brain slices, (2) the reasons for reduced levels of ATP, (3) the possibility of improving cellular ATP, and (4) the functional consequences of raising tissue ATP levels.

\section{Energetic recovery after slice preparation}

In accordance with previous findings (Fredholm et al., 1984; Whittingham et al., 1984a,b), our results show that adenine nucleotide levels in brain slices recover quickly and remain stable for at least $5 \mathrm{~h}$, independently of the incubation temperature. Likewise, the EC and ATP/AMP ratio show a rapid recovery after slice preparation, but it takes $3 \mathrm{~h}$ until they stabilize, well beyond the time conventionally allowed for slices to recover. Provided with an adequate supply of nutrients, it is likely that both interface and submerged slices will recover similarly in terms of adenine nucleotides and energetic parameters. Indeed, TAN and adenosine levels for interface hippocampal slices $(\sim 10.5 \mathrm{nmol} / \mathrm{mg}$ protein and $40 \mathrm{pmol} / \mathrm{mg}$ protein, respectively) (Fredholm et al., 1984) are not different from our results $(\sim 9.8 \mathrm{nmol} / \mathrm{mg}$ protein and 50 $\mathrm{pmol} / \mathrm{mg}$ protein, respectively).

However, it is worth noting that other metabolites, such as cGMP and cAMP, lactate, or phosphocreatine, also require 1-3 h to achieve a steady state (Whittingham et al., 1984b). Likewise, the phosphorylation status of proteins involved in synaptic plasticity, such as GluA1, ERK2, and MEK1/2, changes during the first $3 \mathrm{~h}$ of incubation (Ho et al., 2004), whereas a recovery period of $4 \mathrm{~h}$ has been suggested for achieving stable long-term recordings of LTP in brain slices (Sajikumar and Frey, 2004; Sajikumar et al., 2005; Redondo et al., 2010). 


\section{Temperature dependence of the ATP/AMP ratio and AMPK activity}

Our results indicate that slices maintained at $34^{\circ} \mathrm{C}$ have a significantly higher ATP/AMP ratio compared with slices at room temperature. This is likely attributable to the activity of adenylate kinase (EC 2.7.4.3; 2 ADP $\leftrightarrow$ ATP + AMP), which is greater at temperatures above $32^{\circ} \mathrm{C}$ (Sheng et al., 1999; Lu and Wang, 2008). Accordingly, slices incubated at $22^{\circ} \mathrm{C}$ had a lower ATP/ AMP ratio and showed a threefold higher AMPK activity than slices maintained at $34^{\circ} \mathrm{C}$. This translated into increased phosphorylation of a downstream target, ACC, and suggests that other downstream targets are likely to be similarly affected.

Of the known AMPK targets relevant to synaptic physiology, AMPK phosphorylates $\mathrm{GABA}_{\mathrm{B}}$ receptors (Hardie and Frenguelli, 2007; Kuramoto et al., 2007) and calcium-activated potassium channels (Wyatt et al., 2007). Furthermore, a proteomic screen revealed 12 brain-specific downstream targets of AMPK, including synapsin I and PACSIN1, further suggesting a role for AMPK in regulating synaptic activity (Tuerk et al., 2007). Indeed, enhancing AMPK activity inhibits long-lasting LTP (Potter et al., 2010). Hence, incubating slices at elevated temperatures will more closely replicate metabolism in vivo with respect to the activity of enzymes and properties of synaptic transmission.

\section{Basis of reduced tissue ATP content in brain slices}

As seen in this and many other reports (Mcllwain, 1952; Thomas, 1957; Kass and Lipton, 1982; Fredholm et al., 1984; Whittingham et al., 1989; Paschen and Djuricic, 1995; Milusheva et al., 1996), brain slices have $\sim 40-60 \%$ lower ATP and TAN levels than the in vivo brain (Supplemental References). Our results suggest that this is attributable to the loss of adenine nucleotides and/or their metabolites, especially in hippocampal tissue, during slice preparation. However, incubation of slices in Rib/Ade-supplemented aCSF allowed the tissue to appreciably increase TAN levels. When corrected for the influence of the dead slice edges, which we could model accurately and which agreed with histological estimates we made previously (Frenguelli et al., 2003), TAN levels were within the range reported in vivo. This suggests that the recovery of ATP levels in brain slices is limited by the lack of precursors in the aCSF and does not necessarily reflect an intrinsic metabolic handicap.

\section{Implications of improving the tissue ATP content in brain slices}

Although Rib/Ade restored tissue nucleotide levels close to those observed in vivo, this did not have a bearing on basal synaptic transmission, paired-pulse facilitation, or the tonic handling and effects of extracellular adenosine. Instead, Rib/Ade inhibited LTP after tetanic stimulation and weak TBS. That the application of an $A_{1} R$ antagonist reversed the fatigue of the fEPSP during the tetanus and prevented the decline of tetanus-induced LTP in Rib/ Ade-treated slices suggests that the higher TAN levels resulted in greater activity-dependent adenosine release, thereby preventing the stable expression of LTP. This suggests that endogenous adenosine exerts an inhibitory influence on LTP induction (de Mendonça and Ribeiro, 1994; Forghani and Krnjević, 1995; Fujii et al., 2000; Rex et al., 2005), especially when used with weak stimulation protocols (Arai and Lynch, 1992; de Mendonça and Ribeiro, 2000). Interestingly, the threshold for adenosinedependent regulation of TBS, based on the facilitatory actions of an $\mathrm{A}_{1} \mathrm{R}$ antagonist, was 20 pulses (Arai and Lynch, 1992; de Mendonça and Ribeiro, 2000), consistent with our predictions based on tetanic and TBS cumulative depolarizations and experiments with Rib/Ade-treated slices. These observations and our own results point toward an adenosine $A_{1} R$-dependent regulation of LTP, which is influenced by the levels of intracellular adenine nucleotides.

However, our analysis of the TBS stimulus trains revealed no $\mathrm{A}_{1} \mathrm{R}$-dependent fatigue of the fEPSP. This may reflect the fact that the 200 ms burst spacing may allow time for the removal of extracellular adenosine between stimulus trains through metabolism, reuptake, or diffusion. Thus, to the two known actions of TBS that make it an effective and naturalistic stimulus for LTP induction, maximizing both postsynaptic depolarization and GABAergic fatigue, we may now potentially add a third: minimizing the intraburst synaptic accumulation of extracellular adenosine.

Using adenosine biosensors, we were able to detect in real time the release of adenosine during TBS. Rib/Ade-treated slices released significantly more adenosine, consistent with the availability of a greater precursor pool of ATP. To establish whether ATP or adenosine was released in response to high-frequency stimulation, we used the noncompetitive ectonucleotidase inhibitor POM-1 (Müller et al., 2006; Wall et al., 2008) and the equilibrative nucleoside transporter (ENT) inhibitors DIPY/NBTI (Frenguelli et al., 2007; Etherington et al., 2009). POM-1 failed to reduce, and indeed facilitated, TBS-induced adenosine release. This is unlikely to be attributable to ATP $\mathrm{P}_{2}$ receptor-mediated facilitation of adenosine release reported by others (Almeida et al., 2003) because the facilitation was not affected by the $\mathrm{P}_{2}$ antagonist PPADS. Instead, this facilitation may involve nonspecific actions of POM-1 (Wall et al., 2008) or could potentially involve ATP heteroexchange with adenosine (Sperlágh et al., 2003), which is insensitive to $P_{2}$ receptor antagonists but sensitive to ENT inhibition. Accordingly, DIPY/NBTI caused a 50\% reduction in TBS-induced adenosine release, which is consistent with the direct release of adenosine during high-frequency stimulation (Wall and Dale, 2008; Klyuch et al., 2011).

In a wider context, the reduced tissue ATP levels observed after cerebral ischemia in vivo may, via reduced extracellular adenosine and reduced activation of the anticonvulsant $A_{1} R$ (Boison and Stewart, 2009; Dale and Frenguelli, 2009), contribute to the development of post-ischemic epilepsy (Camilo and Goldstein, 2004; Kadam et al., 2010). Indeed, the influence of intracellular ATP on extracellular adenosine and neuronal excitability has been described recently (Kawamura et al., 2010) and may be the basis for the reduced incidence of seizures during a ketogenic diet (Masino and Geiger, 2008). Accordingly, elevation of tissue ATP levels with Rib/Ade may be of value in the postischemic brain. In fact, Rib has been used to improve postischemic cardiac function in vitro, in vivo, and in humans (Zimmer, 1998; Omran et al., 2003; Shecterle et al., 2010). Although Ade has to be administered with a xanthine oxidase inhibitor (Watts et al., 1974; Simmonds, 1986) to prevent its conversion to an insoluble metabolite, this may be beneficial (Phillis et al., 1995) because it would prevent the formation of nonsalvageable xanthine, thereby providing greater substrates for the purine salvage pathway in the post-ischemic brain. Thus, Rib/Ade may be of value in restoring ATP levels and adenosine release after brain injury.

In summary, the data presented address long-standing issues in the use of brain slices as in vitro models for the mammalian CNS. We confirm the long-held view that tissue adenine nucleotides are $\sim 50 \%$ of the values reported in vivo but demonstrate that this is an underestimate (by $\sim 20 \%$ ) because of the contribution of damaged slice edges. Moreover, we show that slices have 
an appreciable capacity, through the purine salvage pathway, to restore and maintain tissue ATP levels close to in vivo levels when presented with the ATP precursors Ade and Rib. The physiological consequences of elevated tissue ATP levels are in the greater activity-dependent release of adenosine and the raising of the threshold for the induction of LTP.

\section{References}

Almeida T, Rodrigues RJ, de Mendonça A, Ribeiro JA, Cunha RA (2003) Purinergic P2 receptors trigger adenosine release leading to adenosine A2A receptor activation and facilitation of long-term potentiation in rat hippocampal slices. Neuroscience 122:111-121.

Arai A, Lynch G (1992) Factors regulating the magnitude of long-term potentiation induced by theta pattern stimulation. Brain Res 598:173-184.

Atkinson DE (1968) The energy charge of the adenylate pool as a regulatory parameter. Interaction with feedback modifiers. Biochemistry 7:4030-4034.

Baldwin SA, Beal PR, Yao SY, King AE, Cass CE, Young JD (2004) The equilibrative nucleoside transporter family, SLC29. Pflugers Arch 447:735-743.

Barsotti C, Ipata PL (2002) Pathways for alpha-D-ribose utilization for nucleobase salvage and 5-fluorouracil activation in rat brain. Biochem Pharmacol 63:117-122.

Bender E, Buist A, Jurzak M, Langlois X, Baggerman G, Verhasselt P, Ercken M, Guo HQ, Wintmolders C, Van den Wyngaert I, Van Oers I, Schoofs L, Luyten W (2002) Characterization of an orphan G protein-coupled receptor localized in the dorsal root ganglia reveals adenine as a signaling molecule. Proc Natl Acad Sci U S A 99:8573-8578.

Boison D, Stewart KA (2009) Therapeutic epilepsy research: from pharmacological rationale to focal adenosine augmentation. Biochem Pharmacol 78:1428-1437.

Camilo O, Goldstein LB (2004) Seizures and epilepsy after ischemic stroke. Stroke 35:1769-1775.

Chen LY, Rex CS, Sanaiha Y, Lynch G, Gall CM (2010) Learning induces neurotrophin signaling at hippocampal synapses. Proc Natl Acad Sci U S A 107:7030-7035.

Costenla AR, Lopes LV, de Mendonça A, Ribeiro JA (2001) A functional role for adenosine A3 receptors: modulation of synaptic plasticity in the rat hippocampus. Neurosci Lett 302:53-57.

Dale N, Frenguelli BG (2009) Release of adenosine and ATP during ischemia and epilepsy. Curr Neuropharmacol 7:160-179.

Dale N, Pearson T, Frenguelli BG (2000) Direct measurement of adenosine release during hypoxia in the CA1 region of the rat hippocampal slice. J Physiol 526:143-155.

de Mendonça A, Ribeiro JA（1994） Endogenous adenosine modulates longterm potentiation in the hippocampus. Neuroscience 62:385-390.

de Mendonça A, Ribeiro JA (2000) Long-term potentiation observed upon blockade of adenosine A1 receptors in rat hippocampus is $\mathrm{N}$-methyl-Daspartate receptor-dependent. Neurosci Lett 291:81-84.

Edwards FA, Konnerth A, Sakmann B, Takahashi T (1989) A thin slice preparation for patch clamp recordings from neurones of the mammalian central nervous system. Pflugers Arch 414:600-612.

Etherington LA, Patterson GE, Meechan L, Boison D, Irving AJ, Dale N, Frenguelli BG (2009) Astrocytic adenosine kinase regulates basal synaptic adenosine levels and seizure activity but not activity-dependent adenosine release in the hippocampus. Neuropharmacology 56:429-437.

Feig S, Lipton P (1990) N-methyl-D-aspartate receptor activation and Ca2+ account for poor pyramidal cell structure in hippocampal slices. J Neurochem 55:473-483.

Forghani R, Krnjević K (1995) Adenosine antagonists have differential effects on induction of long-term potentiation in hippocampal slices. Hippocampus 5:71-77.

Fredholm BB, Dunwiddie TV, Bergman B, Lindström K (1984) Levels of adenosine and adenine nucleotides in slices of rat hippocampus. Brain Res 295:127-136.

Frenguelli BG, Llaudet E, Dale N (2003) High-resolution real-time recording with microelectrode biosensors reveals novel aspects of adenosine release during hypoxia in rat hippocampal slices. J Neurochem 86:1506-1515.

Frenguelli BG, Wigmore G, Llaudet E, Dale N (2007) Temporal and mechanistic dissociation of ATP and adenosine release during ischaemia in the mammalian hippocampus. J Neurochem 101:1400-1413.
Fujii S, Kuroda Y, Ito K, Kaneko K, Kato H (1999) Effects of adenosine receptors on the synaptic and EPSP-spike components of long-term potentiation and depotentiation in the guinea-pig hippocampus. J Physiol 521:451-466.

Fujii S, Kato H, Ito K, Itoh S, Yamazaki Y, Sasaki H, Kuroda Y (2000) Effects of $\mathrm{A} 1$ and $\mathrm{A} 2$ adenosine receptor antagonists on the induction and reversal of long-term potentiation in guinea pig hippocampal slices of CA1 neurons. Cell Mol Neurobiol 20:331-350.

Gadalla AE, Pearson T, Currie AJ, Dale N, Hawley SA, Sheehan M, Hirst W, Michel AD, Randall A, Hardie DG, Frenguelli BG (2004) AICA riboside both activates AMP-activated protein kinase and competes with adenosine for the nucleoside transporter in the CA1 region of the rat hippocampus. J Neurochem 88:1272-1282.

Gerlach E, Marko P, Zimmer HG, Pechan I, Trendelenburg C (1971) Different response of adenine nucleotide synthesis de novo in kidney and brain during aerobic recovery from anoxia and ischemia. Experientia $27: 876-878$.

Hardie DG (2007) AMP-activated/SNF1 protein kinases: conserved guardians of cellular energy. Nat Rev Mol Cell Biol 8:774-785.

Hardie DG, Frenguelli BG (2007) A neural protection racket: AMPK and the GABA(B) receptor. Neuron 53:159-162.

Hardie DG, Hawley SA (2001) AMP-activated protein kinase: the energy charge hypothesis revisited. Bioessays 23:1112-1119.

Hardie DG, Salt IP, Davies SP (2000) Analysis of the role of the AMPactivated protein kinase in the response to cellular stress. Methods Mol Biol 99:63-74.

Hardie DG, Hawley SA, Scott JW (2006) AMP-activated protein kinasedevelopment of the energy sensor concept. J Physiol 574:7-15.

Hawley SA, Boudeau J, Reid JL, Mustard KJ, Udd L, Mäkelä TP, Alessi DR, Hardie DG (2003) Complexes between the LKB1 tumor suppressor, STRAD alpha/beta and MO25 alpha/beta are upstream kinases in the AMP-activated protein kinase cascade. J Biol 2:28.

Hawley SA, Pan DA, Mustard KJ, Ross L, Bain J, Edelman AM, Frenguelli BG, Hardie DG (2005) Calmodulin-dependent protein kinase kinase-beta is an alternative upstream kinase for AMP-activated protein kinase. Cell Metab 2:9-19.

Ho OH, Delgado JY, O’Dell TJ (2004) Phosphorylation of proteins involved in activity-dependent forms of synaptic plasticity is altered in hippocampal slices maintained in vitro. J Neurochem 91:1344-1357.

Hossmann KA (2008) Cerebral ischemia: models, methods and outcomes. Neuropharmacology 55:257-270.

Kadam SD, White AM, Staley KJ, Dudek FE (2010) Continuous electroencephalographic monitoring with radio-telemetry in a rat model of perinatal hypoxia-ischemia reveals progressive post-stroke epilepsy. J Neurosci 30:404-415

Kass IS, Lipton P (1982) Mechanisms involved in irreversible anoxic damage to the in vitro rat hippocampal slice. J Physiol 332:459-472.

Kawamura M Jr, Ruskin DN, Masino SA (2010) Metabolic autocrine regulation of neurons involves cooperation among pannexin hemichannels, adenosine receptors, and KATP channels. J Neurosci 30:3886-3895.

Kessey K, Mogul DJ (1998) Adenosine A2 receptors modulate hippocampal synaptic transmission via a cyclic-AMP-dependent pathway. Neuroscience 84:59-69.

Klyuch BP, Richardson MJ, Dale N, Wall MJ (2011) The dynamics of single spike-evoked adenosine release in the cerebellum. J Physiol 589:283-295.

Kobayashi M, Lust WD, Passonneau JV (1977) Concentrations of energy metabolites and cyclic nucleotides during and after bilateral ischemia in the gerbil cerebral cortex. J Neurochem 29:53-59.

Kuramoto N, Wilkins ME, Fairfax BP, Revilla-Sanchez R, Terunuma M, Tamaki K, Iemata M, Warren N, Couve A, Calver A, Horvath Z, Freeman K, Carling D, Huang L, Gonzales C, Cooper E, Smart TG, Pangalos MN, Moss SJ (2007) Phospho-dependent functional modulation of GABA(B) receptors by the metabolic sensor AMP-dependent protein kinase. Neuron 53:233-247.

Larson J, Wong D, Lynch G (1986) Patterned stimulation at the theta frequency is optimal for the induction of hippocampal long-term potentiation. Brain Res 368:347-350.

Ljunggren B, Ratcheson RA, Siesjö BK (1974) Cerebral metabolic state following complete compression ischemia. Brain Res 73:291-307.

Lu Q, Wang J (2008) Single molecule conformational dynamics of adenylate kinase: energy landscape, structural correlations, and transition state ensembles. J Am Chem Soc 130:4772-4783. 
Mascia L, Cappiello M, Cherri S, Ipata PL (2000) In vitro recycling of alphaD-ribose 1-phosphate for the salvage of purine bases. Biochim Biophys Acta 1474:70-74.

Masino SA, Geiger JD (2008) Are purines mediators of the anticonvulsant/ neuroprotective effects of ketogenic diets? Trends Neurosci 31:273-278.

McIlwain H (1952) Phosphates of brain during in vitro metabolism: effects of oxygen, glucose, glutamate, glutamine, and calcium and potassium salts. Biochem J 52:289-295.

McIlwain H, Buchel L, Cheshire JD (1951) The inorganic phosphate and phosphocreatine of Brain especially during metabolism in vitro. Biochem J 48:12-20.

Milusheva EA, Dóda M, Baranyi M, Vizi ES (1996) Effect of hypoxia and glucose deprivation on ATP level, adenylate energy charge and $\left[\mathrm{Ca}^{2+}\right] \mathrm{o}-$ dependent and independent release of $\left[{ }^{3} \mathrm{H}\right]$ dopamine in rat striatal slices. Neurochem Int 28:501-507.

Müller CE, Iqbal J, Baqi Y, Zimmermann H, Röllich A, Stephan H (2006) Polyoxometalates: a new class of potent ecto-nucleoside triphosphate diphosphohydrolase (NTPDase) inhibitors. Bioorg Med Chem Lett 16:5943-5947.

Nowak TS Jr, Fried RL, Lust WD, Passonneau JV (1985) Changes in brain energy metabolism and protein synthesis following transient bilateral ischemia in the gerbil. J Neurochem 44:487-494.

Omran H, Illien S, MacCarter D, St Cyr J, Lüderitz B (2003) D-Ribose improves diastolic function and quality of life in congestive heart failure patients: a prospective feasibility study. Eur J Heart Fail 5:615-619.

Paschen W, Djuricic B (1995) Comparison of in vitro ischemia-induced disturbances in energy metabolism and protein synthesis in the hippocampus of rats and gerbils. J Neurochem 65:1692-1697.

Pearson T, Nuritova F, Caldwell D, Dale N, Frenguelli BG (2001) A depletable pool of adenosine in area CA1 of the rat hippocampus. J Neurosci 21:2298-2307.

Phillis JW, Perkins LM, Smith-Barbour M, O'Regan MH (1995) Oxypurinolenhanced postischemic recovery of the rat brain involves preservation of adenine nucleotides. J Neurochem 64:2177-2184.

Potter WB, O'Riordan KJ, Barnett D, Osting SM, Wagoner M, Burger C, Roopra A (2010) Metabolic regulation of neuronal plasticity by the energy sensor AMPK. PLoS One 5:e8996.

Redondo RL, Okuno H, Spooner PA, Frenguelli BG, Bito H, Morris RG (2010) Synaptic tagging and capture: differential role of distinct calcium/ calmodulin kinases in protein synthesis-dependent long-term potentiation. J Neurosci 30:4981-4989.

Rex CS, Kramár EA, Colgin LL, Lin B, Gall CM, Lynch G (2005) Long-term potentiation is impaired in middle-aged rats: regional specificity and reversal by adenosine receptor antagonists. J Neurosci 25:5956-5966.

Sajikumar S, Frey JU (2004) Late-associativity, synaptic tagging, and the role of dopamine during LTP and LTD. Neurobiol Learn Mem 82:12-25.

Sajikumar S, Navakkode S, Frey JU (2005) Protein synthesis-dependent long-term functional plasticity: methods and techniques. Curr Opin Neurobiol 15:607-613.

Sanders MJ, Grondin PO, Hegarty BD, Snowden MA, Carling D (2007) Investigating the mechanism for AMP activation of the AMP-activated protein kinase cascade. Biochem J 403:139-148.

Schurr A, Rigor BM (1989) Cerebral ischemia revisited: new insights as revealed using in vitro brain slice preparations. Experientia 45:684-695.

Shecterle LM, Terry KR, St Cyr JA (2010) The patented uses of D-ribose in cardiovascular diseases. Recent Pat Cardiovasc Drug Discov 5:138-142.

Sheng XR, Li X, Pan XM (1999) An iso-random Bi Bi mechanism for adenylate kinase. J Biol Chem 274:22238-22242.
Siklós L, Kuhnt U, Párducz A, Szerdahelyi P (1997) Intracellular calcium redistribution accompanies changes in total tissue $\mathrm{Na}^{+}, \mathrm{K}^{+}$and water during the first two hours of in vitro incubation of hippocampal slices. Neuroscience 79:1013-1022.

Simmonds HA (1986) 2,8-Dihydroxyadenine lithiasis-epidemiology, pathogenesis and therapy. Verh Dtsch Ges Inn Med 92:503-508.

Sperlágh B, Szabó G, Erdélyi F, Baranyi M, Vizi ES (2003) Homo- and heteroexchange of adenine nucleotides and nucleosides in rat hippocampal slices by the nucleoside transport system. Br J Pharmacol 139:623-633.

Thomas J (1957) The composition of isolated cerebral tissue; purines. Biochem J 66:655-658.

Tuerk RD, Thali RF, Auchli Y, Rechsteiner H, Brunisholz RA, Schlattner U, Wallimann T, Neumann D (2007) New candidate targets of AMPactivated protein kinase in murine brain revealed by a novel multidimensional substrate-screen for protein kinases. J Proteome Res 6:3266-3277.

von Kügelgen I, Schiedel AC, Hoffmann K, Alsdorf BB, Abdelrahman A, Müller CE (2008) Cloning and functional expression of a novel Gi protein-coupled receptor for adenine from mouse brain. Mol Pharmacol 73:469-477.

Wall M, Dale N (2008) Activity-dependent release of adenosine: a critical re-evaluation of mechanism. Curr Neuropharmacol 6:329-337.

Wall MJ, Wigmore G, Lopatár J, Frenguelli BG, Dale N (2008) The novel NTPDase inhibitor sodium polyoxotungstate (POM-1) inhibits ATP breakdown but also blocks central synaptic transmission, an action independent of NTPDase inhibition. Neuropharmacology 55:1251-1258.

Watts RW, McKeran RO, Brown E, Andrews TM, Griffiths MI (1974) Clinical and biochemical studies on treatment of Lesch-Nyhan syndrome. Arch Dis Child 49:693-702.

Whittingham TS, Lust WD, Passonneau JV (1984a) An in vitro model of ischemia: metabolic and electrical alterations in the hippocampal slice. J Neurosci 4:793-802.

Whittingham TS, Lust WD, Christakis DA, Passonneau JV (1984b) Metabolic stability of hippocampal slice preparations during prolonged incubation. J Neurochem 43:689-696.

Whittingham TS, Warman E, Assaf H, Sick TJ, LaManna JC (1989) Manipulating the intracellular environment of hippocampal slices: $\mathrm{pH}$ and highenergy phosphates. J Neurosci Methods 28:83-91.

Woods A, Salt I, Scott J, Hardie DG, Carling D (1996) The alphal and alpha2 isoforms of the AMP-activated protein kinase have similar activities in rat liver but exhibit differences in substrate specificity in vitro. FEBS Lett 397:347-351.

Woods A, Dickerson K, Heath R, Hong SP, Momcilovic M, Johnstone SR, Carlson M, Carling D (2005) $\mathrm{Ca}^{2+} /$ calmodulin-dependent protein kinase kinase-beta acts upstream of AMP-activated protein kinase in mammalian cells. Cell Metab 2:21-33.

Wyatt CN, Mustard KJ, Pearson SA, Dallas ML, Atkinson L, Kumar P, Peers C, Hardie DG, Evans AM (2007) AMP-activated protein kinase mediates carotid body excitation by hypoxia. J Biol Chem 282:8092-8098.

Zimmer HG (1998) Significance of the 5-phosphoribosyl-1-pyrophosphate pool for cardiac purine and pyrimidine nucleotide synthesis: studies with ribose, adenine, inosine, and orotic acid in rats. Cardiovasc Drugs Ther 12 [Suppl 2]:179-187.

zur Nedden S, Eason R, Doney AS, Frenguelli BG (2009) An ion-pair reversed-phase HPLC method for determination of fresh tissue adenine nucleotides avoiding freeze-thaw degradation of ATP. Anal Biochem 388: 108-114. 